ARTICLE

\title{
The structural basis for receptor recognition of human interleukin-18
}

\author{
Naotaka Tsutsumi ${ }^{1, \star}$, Takeshi Kimura ${ }^{2, \star}$, Kyohei Arita ${ }^{3}$, Mariko Ariyoshi ${ }^{1,4}$, Hidenori Ohnishi ${ }^{2}$ \\ Takahiro Yamamoto ${ }^{2}$, Xiaobing Zuo ${ }^{5}$, Katsumi Maenaka ${ }^{6}$, Enoch Y. Park ${ }^{7}$, Naomi Kondo ${ }^{2,8}$, \\ Masahiro Shirakawa ${ }^{1,9}$, Hidehito Tochio $^{10}$ \& Zenichiro Kato ${ }^{2,11}$
}

Interleukin (IL)-18 is a proinflammatory cytokine that belongs to the IL-1 family and plays an important role in inflammation. The uncontrolled release of this cytokine is associated with severe chronic inflammatory disease. IL-18 forms a signalling complex with the IL-18 receptor $\alpha(R \alpha)$ and $\beta(R \beta)$ chains at the plasma membrane, which induces multiple inflammatory cytokines. Here, we present a crystal structure of human IL-18 bound to the two receptor extracellular domains. Generally, the receptors' recognition mode for IL-18 is similar to IL-1及; however, certain notable differences were observed. The architecture of the IL-18 receptor second domain (D2) is unique among the other IL-1R family members, which presumably distinguishes them from the IL-1 receptors that exhibit a more promiscuous ligand recognition mode. The structures and associated biochemical and cellular data should aid in developing novel drugs to neutralize IL-18 activity.

\footnotetext{
${ }^{1}$ Department of Molecular Engineering, Graduate School of Engineering, Kyoto University, Katsura, Nishikyo-ku, Kyoto 615-8510, Japan. ${ }^{2}$ Department of Pediatrics, Graduate School of Medicine, Gifu University, Yanagido 1-1, Gifu 501-1194, Japan. ${ }^{3}$ Graduate School of Nanobioscience, Yokohama City University, 1-7-29 Suehiro-cho, Tsurumi-ku, Yokohama Kanagawa 230-0045, Japan. ${ }^{4}$ Institute for Integrated Cell-Material Sciences, Kyoto University, Kyoto 606-8501, Japan. ${ }^{5}$ X-Ray Science Division, Argonne National Laboratory, 9700 South Cass Avenue, Argonne, Illinois 60439, USA. ${ }^{6}$ Laboratory of Biomolecular Science and Center for Research and Education on Drug Discovery, Faculty of Pharmaceutical Sciences, Hokkaido University, , Kita-12, Nishi-6, Kita-ki, Sapporo 0600812, Japan. ${ }^{7}$ Research Institute of Green Science and Technology, Department of Bioscience, Graduate school of Science and Technology, Shizuoka University, 836 Ohya Suruga-ku, Shizuoka 422-8529, Japan. ${ }^{8}$ Heisei College of Health Sciences, 180 Kurono, Gifu 501-1131, Japan. ${ }^{9}$ Core Research of Evolution Science (CREST), Japan Sciences and Technology Agency, Tokyo 102-0076, Japan. ${ }^{10}$ Department of Biophysics, Graduate School of Science, Kyoto University, Kitashirakawa-oiwake, Sakyo-ku, Kyoto 606-8502, Japan. ${ }^{11}$ Biomedical Informatics, Medical Information Sciences Division, The United Graduate School of Drug Discovery and Medical Information Sciences, Gifu University, Gifu 501-1194, Japan. * These authors contributed equally to this work. Correspondence and requests for materials should be addressed to H.O. (email: ohnishih@gifu-u.ac.jp) or to H.T. (email: tochio@mb.biophys.kyoto-u.ac.jp).
} 
nterleukin (IL)-18 belongs to the IL-1 superfamily and was first discovered as an interferon gamma (IFN- $\gamma$ )-inducing factor in sera from mice with hepatitis stimulated with Propionibacterium acnes and lipopolysaccharide ${ }^{1}$. This proinflammatory cytokine is secreted by various types of cells and strongly augments IFN- $\gamma$ production in type- 1 helper T (Th1) cells and natural killer (NK) cells following activation of NK-cell cytotoxicity; thus, it plays a critical role in inflammation and the host defense against microbes. In addition to IL-1 $\beta^{2,3}$, IL-18 is synthesized as a biologically inactive precursor (proIL18) on activation of a certain class of receptors, such as Toll-like receptors and proinflammatory cytokine receptors, and then stored in the cytosol. Once it matures via caspase-1 (ref. 4), which is regulated by a large protein complex referred to as the inflammasome ${ }^{5}$, IL-18 is extracellularly secreted and binds IL-18 receptor $\alpha(R \alpha)$ as well as IL-18 receptor $\beta(R \beta)$ at the immunocyte plasma membrane in a stepwise manner. IL-18/ IL-18R $\alpha /$ IL-18R $\beta$ ternary complex formation juxtaposes the intracellular Toll-Interleukin-1 receptor domains of IL-18R $\alpha$ and IL-18R $\beta$, to which the adaptor molecule myeloid differentiation factor 88 (MyD88) is recruited presumably with the aid of TRAM ${ }^{6}$. MyD88 further interacts with IL-1 receptor associating kinase (IRAK) 4 and IRAK1/2 to form the large molecular assembly referred to as Myddosome, which subsequently activates IKK via TRAF6. Finally, the signal activates the NF- $\kappa B$ and mitogenactivated protein kinase pathways ${ }^{7}$, which upregulate the expression of various inflammatory cytokines.

Of the IL- 1 family cytokines, IL-18 and IL-1 $\beta$ have garnered much attention because they are causal cytokines that lead to severe chronic inflammatory syndrome. IL- $1 \beta$ is associated with immunological disorders, such as autoinflammatory syndromes ${ }^{8,9}$. The central pathogenic feature of autoinflammatory syndromes is excess production of mature IL- $1 \beta$ derived from abnormal inflammasome activation due to certain gene mutations. IL-1 $\beta$-related autoinflammatory diseases are treated through neutralizing IL-1 $\beta$ by anti-IL-1 $\beta$ (canakinumab and gevokizumab), engineered soluble receptors (rilonacept) or the receptor antagonist IL-1Ra (anakinra), which is remarkably effective; thus, these treatments are currently in clinical use $\mathrm{e}^{10}$. Similar to IL-1 $\beta$, IL-18 overproduction likely leads to severe autoimmune, autoinflammatory, allergic, neurological and metabolic disease, which might be associated with IL-18 or IL-18 receptor genetic polymorphisms ${ }^{11-14}$. Two recent papers have revealed that constitutive activation of the inflammasome caused by single point mutations in NLRC4 is associated with a novel autoinflammatory disorder, and the patient with NLRC4mediated macrophage activation syndrome showed ultra-high circulation levels of IL-18 even after IL-1 blockade ${ }^{15,16}$. Consistent with these observations, therapeutic approaches that block IL-18 activity have been effective in inflammatory disease models ${ }^{17,18}$. Therefore, developing drugs that impede binding between IL-18 and the receptors is clinically important. Generally, the atomic structures of targeted proteins and their complexes play vital roles in drug design. Thus far, despite the reported structures for free IL-18 and its related complexes ${ }^{19-22}$, a structure for the genuine complex between IL-18 and its receptors has not yet been determined.

Previously, we reported a solution structure for IL-18 and identified the functional residues for which mutation markedly decreased its binding affinity for IL- $18 \mathrm{R} \alpha^{19}$. The results suggest that the binary complex between IL-18 and IL-18R $\alpha$ exhibits an essentially identical binding mode to the complex between IL- $1 \beta$ and its receptors (IL-1RI or IL-1RII). However, the binding mode for IL-18R $\beta$, which is the IL-18 co-receptor, to IL- $18 / \mathrm{IL}-18 \mathrm{R} \alpha$ remained ambiguous. Recent structural studies on the ternary complex between IL-1 $\beta$ and its receptors' ectodomains ${ }^{23,24}$ demonstrate that IL-1RAcP, which is the commonly used co-receptor for IL-1 $\alpha$, IL-1 $\beta$, IL-33 and IL-36s, adopted a 'left' binding mode. In this mode, IL-1RAcP binds the IL-1 $\beta /$ IL-1RI or IL-1 $\beta /$ IL-1RII binary complexes from the left side as seen from the concave IL-1 $\beta$ recognition surface of IL-1RI or IL-1RII. Furthermore, the other IL-1 superfamily molecule, IL-33/ST2/IL1RAcP, was also suggested to adopt the 'left' binding mode based on the model structure from the small angle X-ray scattering (SAXS) profiles ${ }^{25}$. Thus, left binding seems common in complexes that employ IL-1RAcP. In contrast to other IL-1 family cytokines, IL-18 is unique due to its pair of specialized receptors (IL-18R $\alpha$ and IL-18R $\beta$ ); hence, the recognition details are not sufficiently understood based only on homology to the IL-1 $\beta$ and IL-33 system.

Here, we performed X-ray crystallography using human IL-18 and its complexes with the receptors' extracellular domains. The structures demonstrate that the co-receptor (IL-18R $\beta$ ) binding mode is generally identical to IL-1 $\beta$; however, substantial differences were observed in the subdomain orientations and interaction details throughout the complex. Intriguingly, the second domain (D2) of the two IL-18 receptors lacked one $\beta$-strand, $\mathrm{d} 2$, which is conserved among other IL-1-related receptors, and was previously shown to contribute to the interreceptor interaction. In addition, $\mathrm{N}$-linked glycans played a role in bridging the two receptors, which was observed in the signalling IL-1 $\beta$ receptor complex but was absent in its decoy complex. We further show that other IL-18R $\alpha$ N-linked glycans proximal to IL-18 in the complexes contributed to the binding affinity. With the associated biochemical and cell biological data, the structures comprehensively clarify the IL-18 receptor recognition mode, which will facilitate rational drug development to neutralize IL-18 activity, the uncontrolled release of which has been shown to cause severe chronic inflammatory diseases.

\section{Results}

Structural comparison between the IL-18 and IL-1 $\beta$ complexes. We determined the crystal structures of IL-18 (Fig. 1a), the IL-18/ IL-18R $\alpha$ binary complex (Fig. 1b) and the IL-18/IL-18R $\alpha / \mathrm{IL}-$ $18 \mathrm{R} \beta$ signalling ternary complex (Fig. 1c,d) at the resolutions $2.33,3.10$ and $3.10 \AA$, respectively. The crystallographic statistics are provided in Table 1.

IL-18R $\alpha$ curls around IL-18, and IL-18R $\beta$ contacts the lateral portion of the IL-18/IL-18R $\alpha$ binary complex in a similar manner as the IL-1 $\beta /$ IL-1RI(RII)/IL-1RAcP complex ${ }^{23,24}$. The IL-18 structure essentially does not change on complex formation, maintaining the $\beta$-trefoil fold that comprises $12 \beta$-strands $(\beta 1-\beta 12)$ and $2 \alpha$-helices $(\alpha 1-\alpha 2)$ (Supplementary Fig. 1a), as previously reported ${ }^{19}$. The IL- $18 \mathrm{R} \alpha$ ectodomain folds into three immunoglobulin (Ig)-like domains, which are referred to as D1, D2 and D3, in the same manner as the IL-1 receptors ${ }^{23,24,26}$. Each domain comprises a two-layer sandwich of six to nine $\beta$-strands and contains at least one intra-domain disulfide bond (Supplementary Fig. 1b). Within IL-18R $\alpha$, D1 extensively contacts D2, whereas D3 is distant and is connected by the long D2-D3 linker (Fig. 1d middle), which implies that D1 and D2 behave as a single module, similar to IL-1-related primary receptors. In the Ig superfamily, including the IL-1 receptor family (Fig. 2a), the core cysteine residues on the $\mathrm{b}$ and $\mathrm{f}$ strands are highly conserved (Fig. 2b). However, for IL-18R $\alpha$-D1, the $f$ strand cysteine is replaced with phenylalanine (Fig. 2b), which yields two unexpected surface disulfide bonds (Fig. 2c). In addition, the D2 domain lacks one $\beta$-strand (d2 in Fig. $2 \mathrm{~b}, \mathrm{~d})$ that is structurally conserved among most IL-1 receptor family members, IL-1RI, IL-1RII and ST2 as well as IL-1RAcP.

On ternary complex formation, the IL-18/IL-18R $\alpha$ binary complex structure essentially does not change; the root mean 
a

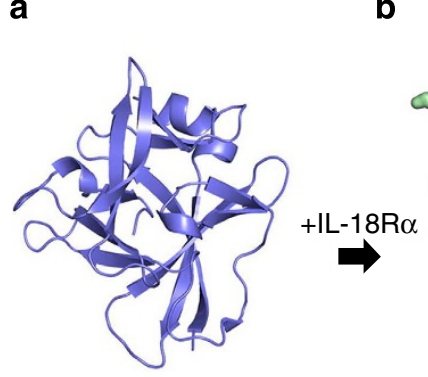

IL-18

b
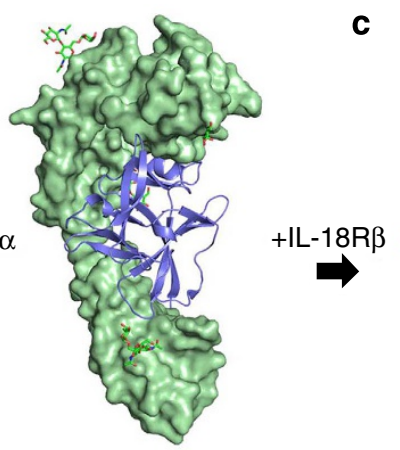

C
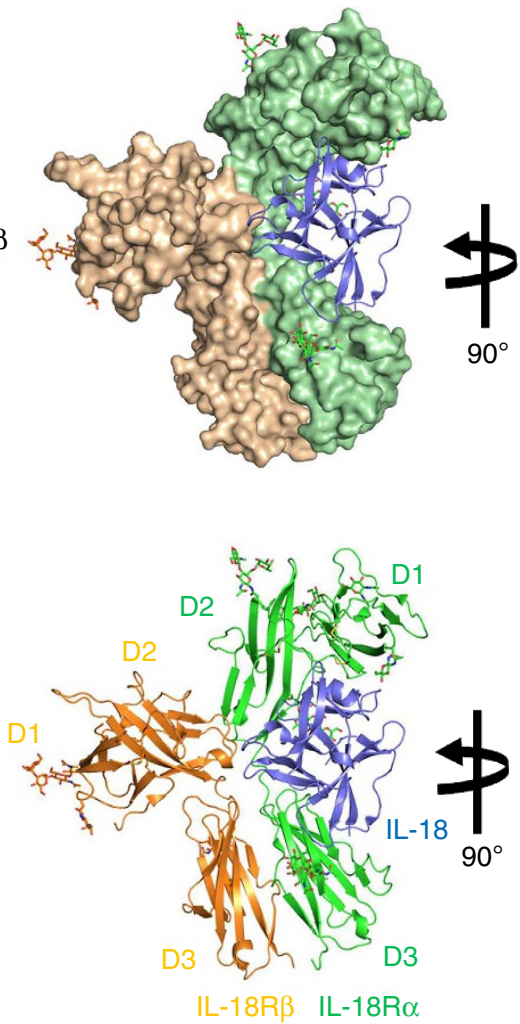
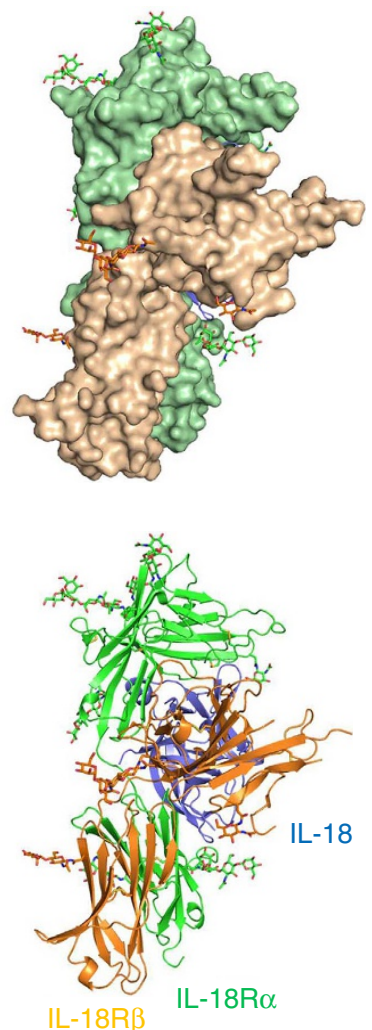

Figure 1 | Overall structures for IL-18 and its extracellular complexes. (a-c) Schematic flow diagram of the stepwise complex formation for IL-18/ IL-18R $\alpha /$ IL-18R $\beta$. Crystal structures of (a) IL-18, (b) IL-18/IL-18R $\alpha$ and (c) IL-18/IL-18R $\alpha /$ IL-18R $\beta$ are shown as a ribbon (IL-18, blue) or surface (IL-18R $\alpha$, palegreen; IL-18R $\beta$, wheat) representation, respectively. (d) Ribbon diagrams of the ternary complex structure for IL-18 (blue), IL-18R $\alpha$ (green) and IL-18R $\beta$ (orange) from three perspectives.

square deviations (RMSD) for the backbone $\mathrm{C} \alpha$ atoms are 0.41-0.90 $\AA$ compared with the asymmetric unit (ASU) molecules. IL-18R $\beta$ is also composed of three Ig-like domains, similar to IL-18R $\alpha$ except for the aforementioned disulfide bonds (Supplementary Fig. 1c); however, the spatial arrangement of these domains is markedly distinct from IL-18R $\alpha$ in the ternary complex (Fig. 1d). D2 and D3 of IL-18R $\beta$ are close to each other and directly associated with IL-18/IL-18R $\alpha$, while D1 does not contribute to ternary complex formation. In fact, a part of the IL-18R $\beta$-D1 electron density is ambiguous presumably because the region was loosely packed in the crystal (Supplementary Fig. 2). The D1 isolation of the co-receptor was also observed previously in the IL-1 $\beta / \mathrm{IL}-1 \mathrm{RI}(\mathrm{RII}) / \mathrm{IL}-1 \mathrm{RAcP}$ complex, where IL-1RAcP-D1 is outstretched and does not participate in the molecular interface. Despite of the similarity in the binding mode, relative orientation of IL-18R $\beta-\mathrm{D} 2+\mathrm{D} 3$ to IL-18/IL-18R $\alpha$ is different from that of IL-1RAcP-D2 + D3 to IL-1 $\beta /$ IL-1RI(RII) $($ Fig. $3 \mathrm{a}-\mathrm{c})$. This difference in the orientations is attributable to the interaction manner at the interface between IL-18R $\beta$-D2 and IL-18/IL-18R $\alpha$ (Fig. 3b,d). Owing to the aforementioned absence of the $\mathrm{d} 2$ strands in D2s (Fig. $2 \mathrm{~b}, \mathrm{~d}$ ), IL-18R $\alpha$-D2 and IL-18R $\beta-\mathrm{D} 2$ supply only two strands (b2 and e2) and loops at the interface, respectively, while for IL-1RI(RII) and IL-1RAcP-D2, three strands (b2, e2 and d2) and loops interact (Fig. 1d and Fig. 3a-c). Furthermore, IL-18R $\beta$-D2 supplies not only electrostatic side chains but also aromatic rings that interact with IL-18, whereas IL-1RAcP-D2 utilizes electrostatic and aliphatic side chains for ligand binding. The $\beta 4-\beta 5$ loop of IL- 18 and IL- $18 R \beta$ D3 do not interact, which may also contribute to the orientation difference (Fig. 3d). A more marked dissimilarity is observed for the IL-18R $\beta$-D1 orientation relative to -D2, which differs from
IL-1RAcP in the complex (Fig. 3e). As a result, despite the same 'left' binding mode, the spatial arrangements of the subdomains in the IL-18/IL-18R $\alpha /$ IL-18R $\beta$ ternary complex differ somewhat from IL-1 $\beta /$ IL-1RI/IL-1RAcP with $\mathrm{C} \alpha$ atom RMSD values of $6.64-6.73 \AA$.

The binding interface between IL-18 and IL-18R $\alpha$. IL-18R $\alpha$ recognizes IL-18 through a large interaction surface area at $\sim 1,850 \AA^{2}$. Two IL-18 sites, Sites I and II, contact IL-18R $\alpha$; Site I is located on a side of the core barrel of the $\beta$-trefoil structure, and Site II is at the top of the $\beta$-barrel (Fig. 4a).

Our previous NMR study showed that the residues 34 to 42 are flexible despite partial $\alpha$-helix formation in this region (residues $38-41)^{19}$. In addition, two isomeric forms that originate from a cis or trans peptide bond between Ala42 $2^{\mathrm{IL}-18}-\mathrm{Pro} 43^{\mathrm{IL}-18}$ in the loop are equally populated in the solution structure. The flexible nature of the segment produces a variety of architectures, as demonstrated in several crystallographic reports, including a loop with a trans isomer ${ }^{22}$, an $\alpha$-helix with a cis isomer ${ }^{21}$ or, primarily, unobservable flexible loop with a trans isomer ${ }^{20,22}$ (Fig. $4 a-c$ ). In both the binary and ternary complexes, the segment between residues 35 and 40 adopts an $\alpha$-helix structure with a cis Ala $42^{\mathrm{IL}-18}-$ Pro $43^{\mathrm{IL}-18}$ bond, which is stabilized by hydrogen bonds and electrostatic interactions with IL-18R $\alpha$ (Fig. 4c).

Surrounding Site I, $\alpha$-helix I mediated the interaction (Fig. $4 \mathrm{c}$ and Fig. 5a), wherein the $\operatorname{Arg} 25^{\mathrm{R} \alpha}$ side chain is buried within the $\beta 3-\alpha 1$ acidic groove of IL-18. Two disulfide bonds, Cys $22^{\mathrm{R} \alpha}$. Cys $41^{\mathrm{R} \alpha}$ and $\mathrm{Cys} 43^{\mathrm{R} \alpha}$-Cys81 ${ }^{\mathrm{R} \alpha}$, bridge the b1-c1 loop to the N-terminal loop and d1-el turn, respectively (Figs $2 \mathrm{c}$ and $5 \mathrm{a}$ ), which likely reinforce the proximal loop structure, to which the long $\beta 10-\beta 11$ hairpin of IL-18 is fitted. This unique feature 
Table 1 | X-ray crystallographic statistics of IL-18 and its extracellular complexes.

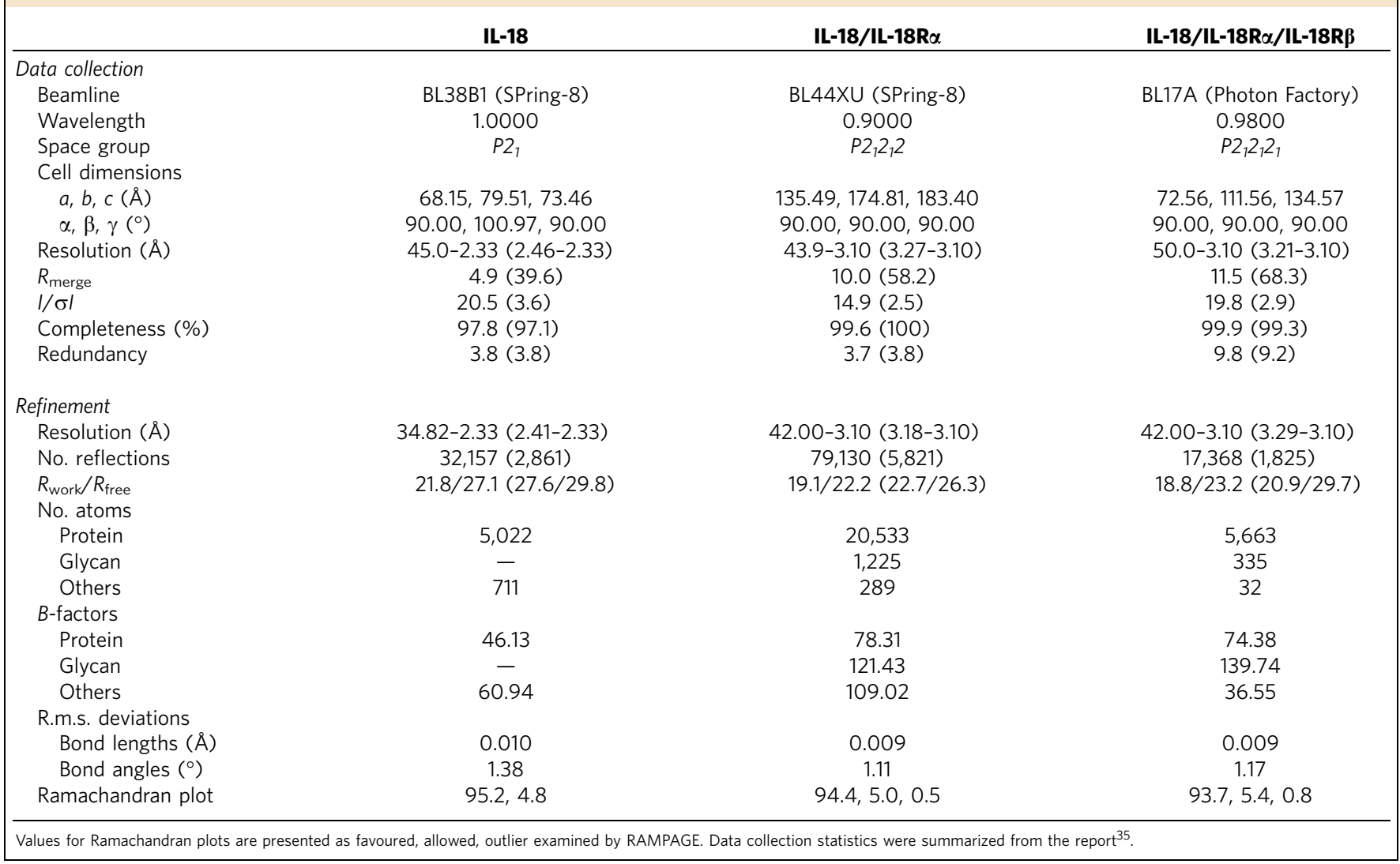

implies that the loop structure may be loosened under certain reductive conditions, which affects the affinity for the ligand. The Ser $42^{\mathrm{R} \alpha}$ amide proton supplies a hydrogen bond for the Asp132 1 IL-18 side chain, which also exhibited a backbonebackbone hydrogen bond with $\mathrm{Cys} 22^{\mathrm{R} \alpha}$. Around Site II (Fig. 5b), the IL-18R $\alpha$ acidic surface, which is composed of the Glu253 ${ }^{\mathrm{R} \alpha}$ and Glu263 ${ }^{\mathrm{R} \alpha}$ carboxylates as well as $\operatorname{Trp} 249^{\mathrm{R} \alpha}$ backbone oxygen, captures the Lys $53^{\mathrm{IL}-18} \varepsilon$-amino group.

IL-18R $\beta$ recognition by IL-18/IL-18R $\alpha$. The IL-18/IL-18R $\alpha / \mathrm{IL}-$ $18 \mathrm{R} \beta$ signalling ternary complex is formed by IL-18R $\beta$ binding with the lateral portion of the binary complex (Fig. 1). The IL-18R $\beta-D 2$ convex surface with the key Tyr212 ${ }^{\mathrm{R} \beta}$ aromatic residue fits into the concave surface jointly formed by IL-18 and IL-18R $\alpha$-D2 (Fig. 5c and Supplementary Fig. 3a) with a $613 \AA^{2}$ buried surface area, which is shallower than that in the IL-1 $\beta$ complexes. The concave surface area is divided into Site III on IL-18 (354 $\AA^{2}$, Fig. 5c) and part of IL-18R $\alpha$-D2 $\left(259 \AA^{2}\right.$, Supplementary Fig. 3a). Note that IL-18 Site III is revised in this work $^{19}$. Site III of IL-18 comprises the prominent $\beta 8$ - $\beta 9$ hairpin and $\beta 11-\alpha 2$ loop (Fig. $5 c$ ), where the aromatic ring of His $109^{\mathrm{IL}-18}$ forms $\pi-\pi$ stacking with $\operatorname{Tyr} 212^{\mathrm{R} \beta}$ at a $3.4 \AA$ distance, which is surrounded and stabilized by multiple hydrogen bonds. IL-18R $\alpha$ D2 is composed of an antiparallel $\beta$-sheet formed by b2 and e2 (Supplementary Fig. 3a) but lacks the conserved $\mathrm{d} 2$ strand compared with the corresponding $\beta$-sheets of IL-1RI and ST2. Although the structure of IL-36R has not been determined yet, the multiple sequence alignment suggests that the b2/e2/d2 sheet is conserved among the primary receptors (Fig. 1b and Supplementary Fig. 1b). In addition to these interactions, IL-18R $\beta$-D3 extensively contacts IL-18R $\alpha$-D3 with the buried area $\sim 550 \AA^{2}$, to which both electrostatic (Supplementary
Fig. 3b) and hydrophobic interactions (Supplementary Fig. 3c) contribute. These inter-receptor interfaces in the IL-1 $\beta$ complex are designated as Site $I^{23}$, in which the IL-1 $\beta \quad \beta 4-\beta 5$ loop interacts with IL-1R1-D3 and IL-1RAcP-D3 to at least partly establish the ligand's agonism/antagonism. The same would be true for the IL-36 system based on the crystal structure of IL-36 (ref. 27). In contrast, the corresponding IL-18 loop does not contact IL-18R $\beta$-D3 and only interacts with IL-18R $\alpha$-D3 (Fig. 3d).

$\mathrm{N}$-linked IL-18R $\alpha$ glycans and its interactions. In the IL-18/IL$18 \mathrm{R} \alpha$ and IL-18/IL-18R $\alpha /$ IL-18R $\beta$ crystal structures, seven $\mathrm{N}$-linked glycosyl chains were identified in IL-18R $\alpha$ at Asn91, 102, 150, 197, 203, 236 and 297 (Fig. 6a). These carbohydrates are high-mannose glycans (Fig. 6b) because the receptor proteins were prepared using the Sf9 expression system. The glycan on Asn $197^{\mathrm{R} \alpha}$, which are located in the D2 domain, forms moderate intramolecular interactions with $\operatorname{Arg} 114^{\mathrm{R} \alpha}$ and $\operatorname{His} 117^{\mathrm{R} \alpha}$ at the D1-D2 loop (Fig. 6c), seemingly contributing to the subdomains' spatial arrangement. The core-NAG (N-acetyl-D-glucosamine) directly linked to Asn $297^{\mathrm{R} \alpha}$ branches into the second-NAG and L-fucose (FUC), which is referred to as the core-FUC (Fig. 6b-d). Interestingly, the core-FUC and second-NAG on Asn $297^{\mathrm{R} \alpha}$ are proximal to the $\beta 4-\beta 5$ loop of IL-18 $(<4 \AA)$; hence, they likely interact through electrostatic and hydrophobic interactions with the ligand (Fig. 6d) and partly contribute the unique D3:D3 interaction.

Notably, the NAG-NAG extended from the IL-18R $\alpha-\mathrm{D} 3$ Asn $236^{\mathrm{R} \alpha}$ and points to the receptor C-terminus in the binary complex; however, in the ternary complex, the NAG-NAG chain changes direction and points to IL-18R $\beta$-D3 within the distance possibly to form electrostatic interaction with $\mathrm{Val} 257^{\mathrm{R} \beta}$ and Asp259 ${ }^{\mathrm{R} \beta}$ (Fig. 6e). A similar inter-receptor interaction via an 


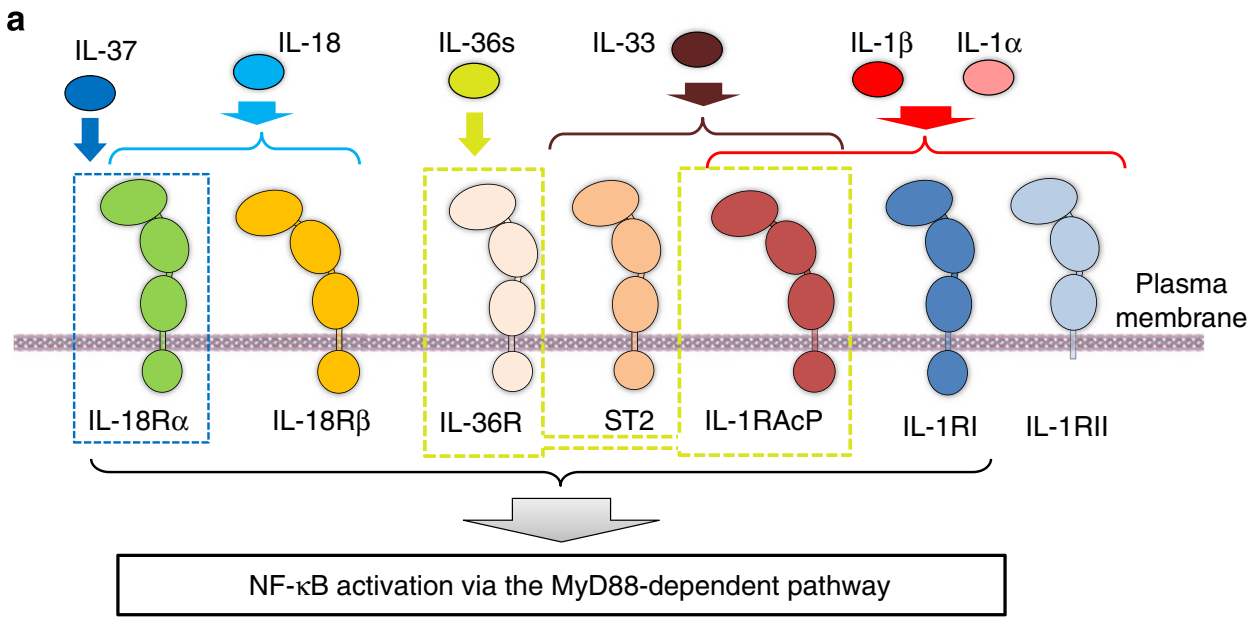

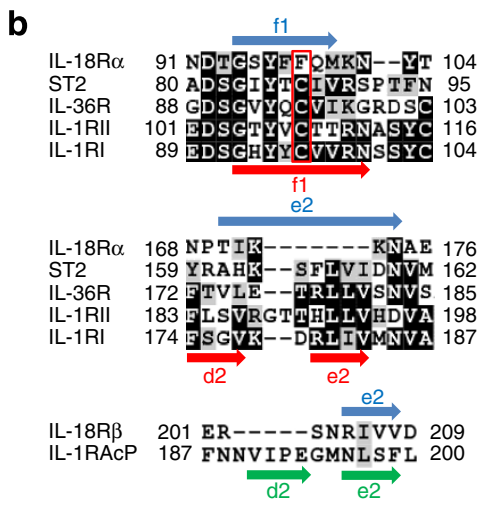

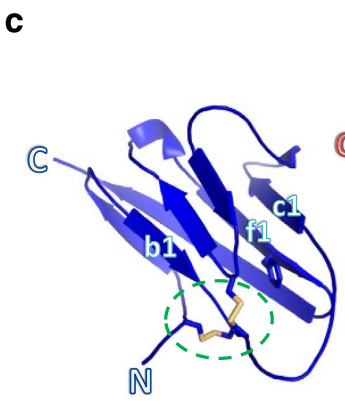

IL-18R $\alpha$-D1

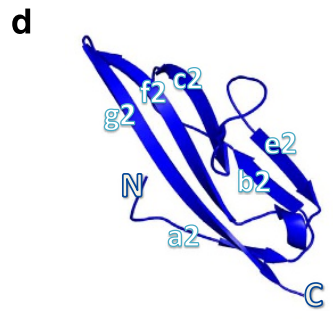

IL-18R $\alpha-D 2$

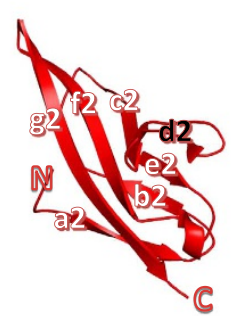

IL-1RI-D2

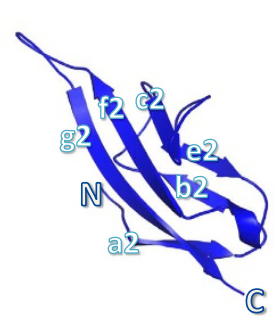

IL-18R $\beta-D 2$

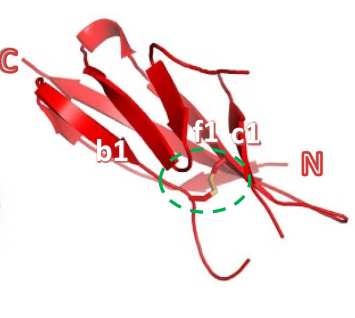

IL-1RI-D1

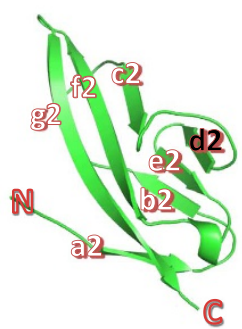

IL-1RAcP-D2

Figure 2 | Structural features of IL-18 and its receptors. (a) Promiscuous interactions between the IL-1 family agonists and IL-37 with the receptor molecules. Except IL-18, all agonists employ IL-1RAcP as a co-receptor, while IL-18 uses IL-18Rß. (b) Certain regions of the receptor multiple sequence alignments manifest the unique qualities of IL-1R family IL-18Rs. The full set of sequence alignments is in Supplementary Fig. 1. (c) Structural comparison of D1 and (d) D2 of the receptors from the signalling complex. The green circles in (c) show the disulfide bond positions.

$\mathrm{N}$-linked oligosaccharide was previously observed between IL-1RI-D3 and IL-1RAcP-D3 in the IL-1 $\beta$ signalling complex, but it is intriguingly absent in the IL-1 $\beta /$ IL-1RII/IL-1RAcP non-signalling decoy complex, which suggests that the N-linked oligosaccharides bridging the two receptors are important for IL-1 family signal transduction.

Characterization of IL-18/IL-18R $\alpha / \mathrm{IL}-18 R \beta$ in solution. A previous SPR analysis showed that IL-18R $\beta$ does not bind free IL-18, but it does bind a preformed IL-18/IL-18R $\alpha$ binary complex ${ }^{19}$. To better understand the formation of this complex under more physiological conditions, we performed titration experiments using solution NMR spectroscopy. The ${ }^{1} \mathrm{H}-{ }^{15} \mathrm{~N}$ correlation spectrum for $\left[{ }^{2} \mathrm{H},{ }^{15} \mathrm{~N}\right]$-IL-18 did not change on adding a small excess of IL-18R $\beta$, indicating that the molecules do not interact. However, marked spectral changes were observed when IL-18 was titrated with IL-18R $\alpha$ (Supplementary Fig. 4a,b). The amino-acid residues that were perturbed during the titration are at the molecular interface of the binary complex, which indicates that the binding mode in solution is identical to the crystal structure (Supplementary Fig. 4b, bottom). Cross-saturation NMR experiments ${ }^{28}$ further confirmed this result with more precision (Fig. 7a, forest and Supplementary Fig. 4c). Next, IL-18R $\beta$ was added to the preformed $\left[{ }^{2} \mathrm{H},{ }^{15} \mathrm{~N}\right]$-IL$18 /$ IL-18R $\alpha$ binary complex. The ${ }^{1} \mathrm{H}-{ }^{15} \mathrm{~N}$ correlation spectrum was then changed due to ternary complex formation. Although significant changes were not observed in the region including the previously defined Site III (Supplementary Fig. 4d), the crosspeaks that disappeared or shifted on ternary complex formation (Supplementary Fig. 4e) are mostly at the interface with IL-18R $\beta$, which is consistent with the ternary complex crystal structure (Fig. 7a, orange). Furthermore, we performed SAXS to analyse the architecture of the ternary complex (Supplementary Fig. 4f-h); these data were used to construct a low-resolution dummy atom model. The crystal structure of the complex reasonably fits the SAXS-derived model envelope (Fig. 7b). Together, the crystal 
a

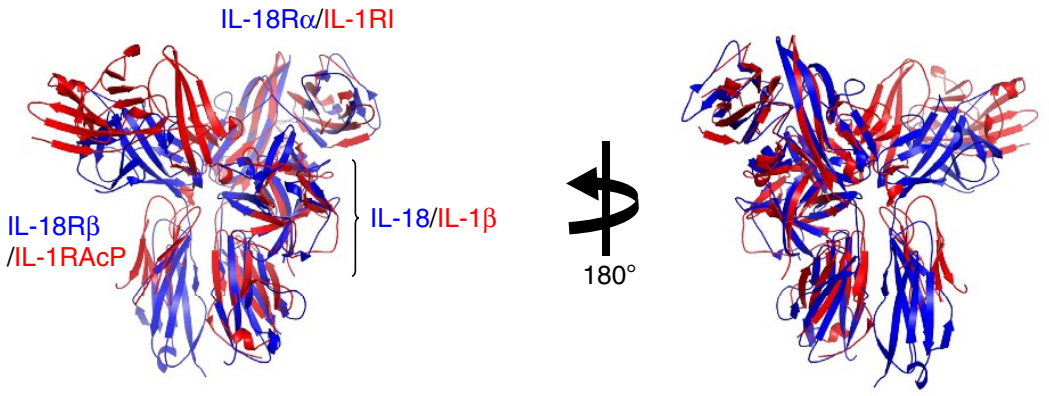

b

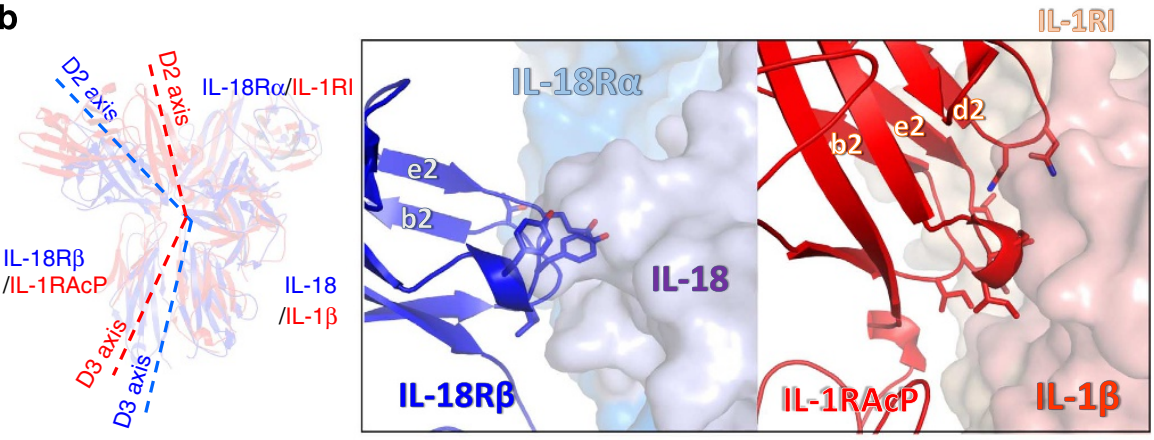

C
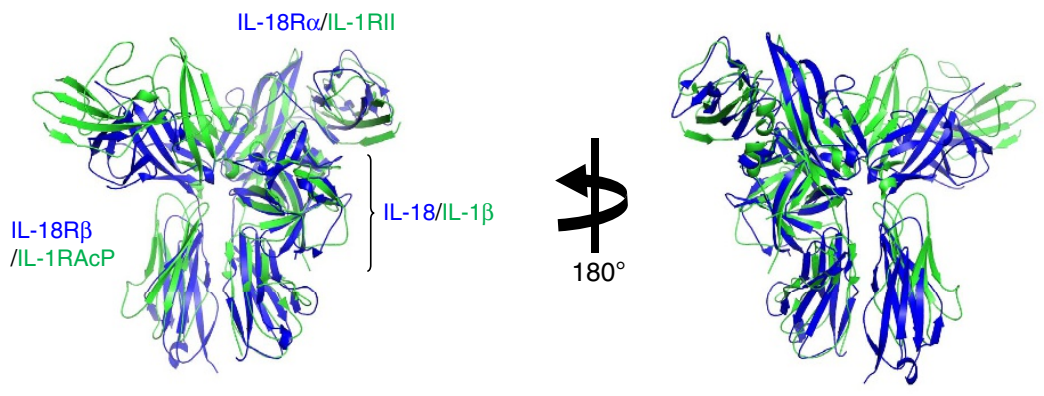

d

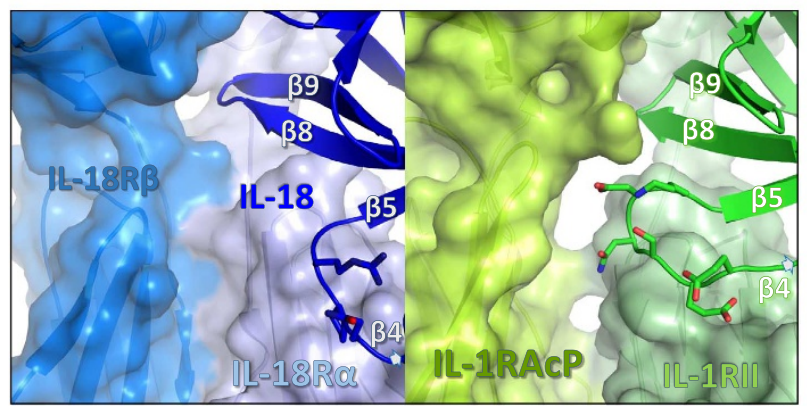

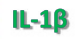

e

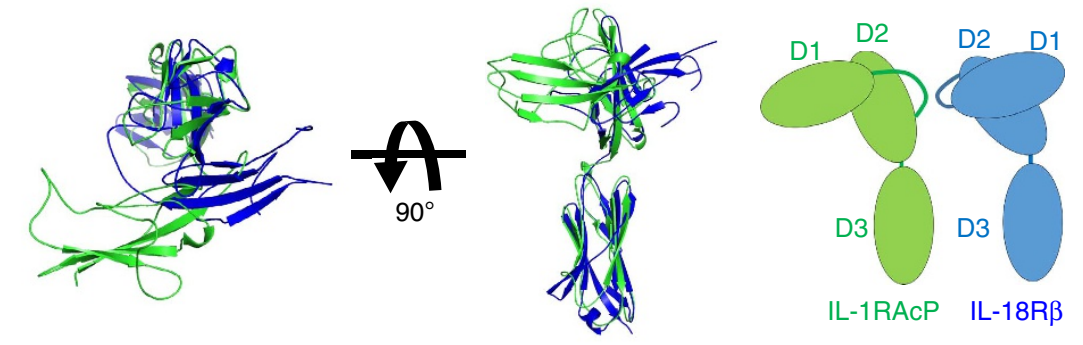

Figure 3 | Structural comparison of the IL-1 family cytokine ternary complexes. (a) Structural alignment of IL-18/IL-18R $\alpha /$ IL-18R $\beta$ (blue) and IL-1 $\beta / I L-1 R I /$ IL-1RAcP (4DEP, red) using the binary complex region. The backbone C $\alpha$ RMSD between IL-18/IL-18R $\alpha$ and IL-1 $13 /$ IL-1RI is $4.35-4.36 \AA$. (b) The orientation of D2 and D3 from IL-18R $\beta$ and IL-1RAcP in the complexes. The dotted lines show the approximate orientation of the longitudinal D2 and D3 axes. A close-up of the binary complex interface, which recognizes the co-receptor protein D2 domains, is also shown. (c) A comparison of IL-18/IL-18R $\alpha$ / IL-18R $\beta$ (blue) and IL-1 $\beta /$ IL-1RII/IL-1RAcP (304O, green). The backbone C $\alpha$ RMSD was $4.39 \AA$ surrounding the binary complex portion. (d) A close-up of the $\beta 4-\beta 5$ loops of the ligands in IL-18/IL-18R $\alpha /$ IL-18R $\beta$ (left) and IL-1 $\beta /$ IL-1RII/IL-1RAcP (right). (e) Superimposition of IL-18R $\beta$ and IL-1RAcP (from 304O). The IL-18Rß-D1 orientation relative to D2 is the opposite of IL-1RAcP. 

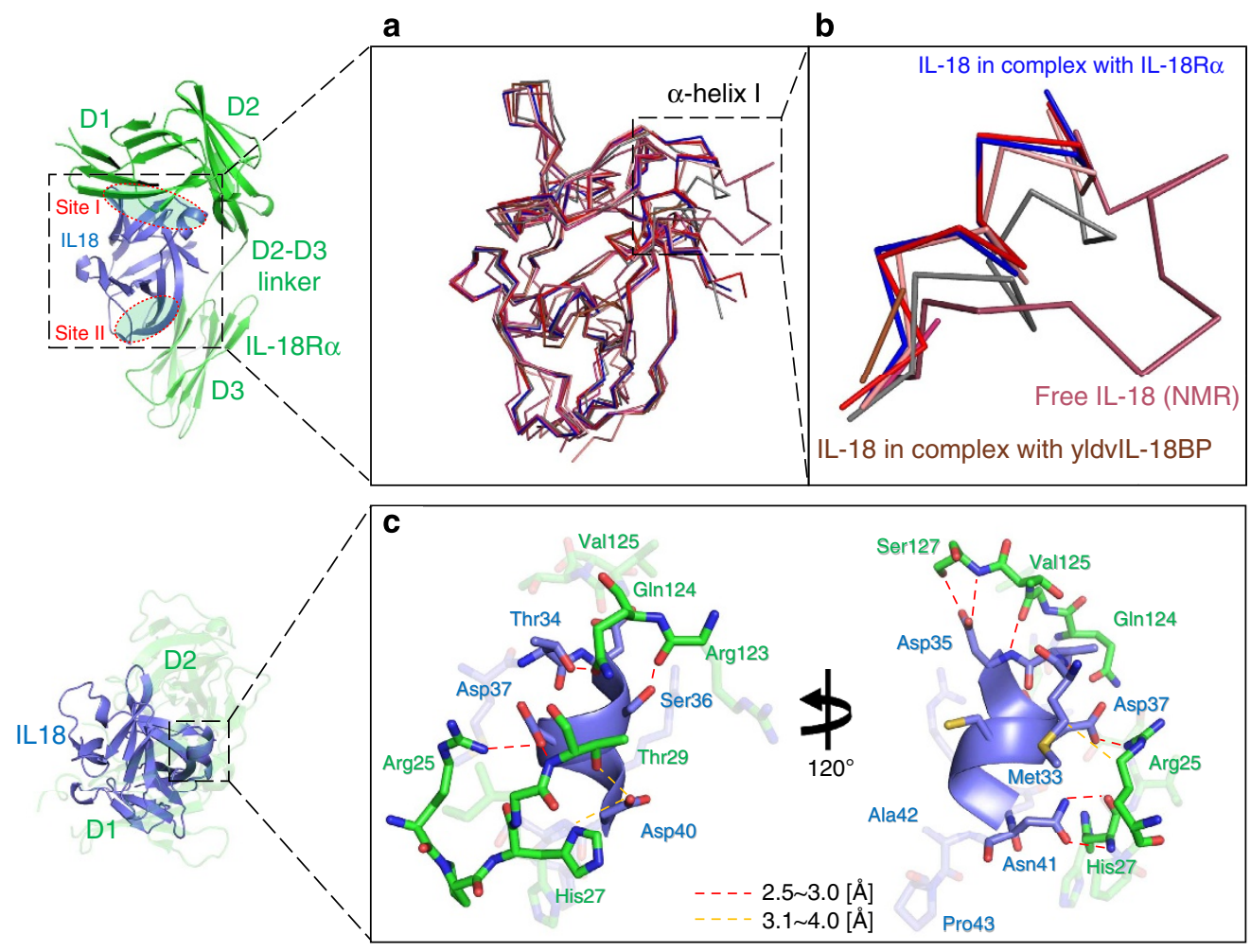

Figure 4 | IL-18 structural perturbations on binding IL-18R $\alpha$ or other proteins. (a) Superimposition of the structures of IL-18 in free and various complex forms: crystal structure of IL-18 with CHPAS (red); the solution structure (1JOS, raspberry); the crystal structure of IL-18 in complex with Ectromelia virus IL-18BP (3F62, pink); the crystal structure of IL-18 complexed with murine reference antibody 125-2H Fab (2VXT, salmon); the crystal structure for IL-18 in complex with YLDV 14L IL-18BP (4EEE, brown); the crystal structure for IL-18 in complex with a DVD-Ig molecule (4HJJ, gray); the crystal structure of IL-18 in complex with IL-18R $\alpha$ (blue). (b) The zoom window of the dashed line box shown in $2 \mathbf{a}$. (c) The stabilized structure and IL-18 $\alpha$-helix I interactions. The structure of IL-18 $\alpha$-helix I stabilized by interactions with IL-18R $\alpha$.

structures solved in this study are consistent with the data collected in the solution state, which underscores the physiological significance of the crystal structures.

Effects of mutation on the signaling and binding affinities. To confirm the importance of the IL-18 Site III interactions in signal transduction, we performed cell-based assays using IL-18R $\beta$ mutants (Fig. 8a). IL-18R $\beta$-WT and its mutants were transiently expressed in HEK293 cells with a background of stably expressed IL- $18 R \alpha$; the NF- $\kappa B$ activity was measured using the luciferase reporter system with or without an IL-18 stimulus. A complete loss of function was observed for the IL-18R $\beta$-E210A-Y212AY214A triple mutants, while IL-18R $\beta$-E210A, -Y212A and K313A exhibited approximately half the activity compared with WT. Remarkably, only a minor decrease in activity was observed when the D1 region of IL-18R $\beta$ was deleted $(\Delta 15-65$ and $\Delta 15-$ 146, Fig. 8b), likely because IL-18R $\beta$-D1 is distal to the other parts of the ternary complex and seemingly does not affect binding. However, a substantial decrease in activity was observed when the D1-D2 loop $(\Delta 15-153)$ was deleted, and the activity was fully abolished in the D1/D2-deficient experiments $(\Delta 15-176$ and $\Delta 15-243)$. Therefore, IL-18R $\beta-\mathrm{D} 2+\mathrm{D} 3$ is sufficient, but D1 is not essential for signalling.

To identify the amino-acid residues that are critical for ternary complex formation, we performed a binding study using surface plasmon resonance (SPR) analysis (Supplementary Figs 5 and 6 and Supplementary Table 1). The prominent binding residues are summarized in Table 2 and Supplementary Fig. 7. First, IL-18R $\beta$ was immobilized on the sensor chip, and binary complexes that formed between one of IL-18 mutants and IL-18R $\alpha$ were examined for binding. When the binary complex contained either of three IL-18 mutants, G108A, H109A or K112A, it lost affinity for IL-18R $\beta$, even though these mutants maintained full binding activity for IL-18R $\alpha$. Thus, the mutated residues are only important for IL-18R $\beta$ binding. Next, one of IL-18R $\beta$ mutants was immobilized on the sensor chip, and the IL-18/IL-18R $\alpha$ binary complex was examined for binding. Our data show that IL-18R $\beta$-Y212A did not bind the binary complex, which is consistent with the structure, wherein substantial $\pi-\pi$ stacking were observed between Tyr212 $2^{\mathrm{R} \beta}$ and His109 $9^{\mathrm{IL}-18}$ (Fig. 5c). IL-18R $\beta-K 313 \mathrm{~A}$ and -E210A exhibited 7- and 20-fold lower affinity for the IL-18/IL-18R $\alpha$ complex relative to the wild-type receptor, respectively. These data are also consistent with the $\mathrm{NF}-\kappa \mathrm{B}$ luciferase reporter assay and the structure, wherein the mutated residues extensively interact with His $109^{\mathrm{IL}-18}$,

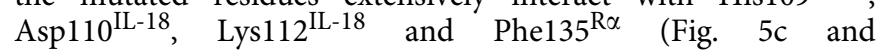
Supplementary Fig. 3a).

To determine the contribution of the IL-18R $\alpha$ N-linked oligosaccharides to the receptor complex formation, we mutated two IL- $18 \mathrm{R} \alpha$ asparagine residues to glutamine (Table 2). The affinity of IL-18 for IL- $18 R \alpha$ decreased to one-third when Asn $297^{\mathrm{R} \alpha}$ was mutated to Gln compared with the wild type, which indicates that the sugar chain is important for the recognition of ligand, wherein the Asn $297^{\mathrm{R} \alpha}$ core-FUC and second-NAG are proximal to IL-18 (Fig. 6d). However, we did not observe a different affinity on mutating Asn $236^{\mathrm{R} \alpha}$.

\section{Discussion}

It is well-known that the IL-1 family system has only two co-receptors, IL-1RAcP and IL-18R $\beta$, despite its seven agonists (IL-1 $\alpha$, IL-1 $\beta$, IL-18, IL-33, IL-36 $\alpha$, IL-36 $\beta$ and IL-36 $\gamma$ ) and four 

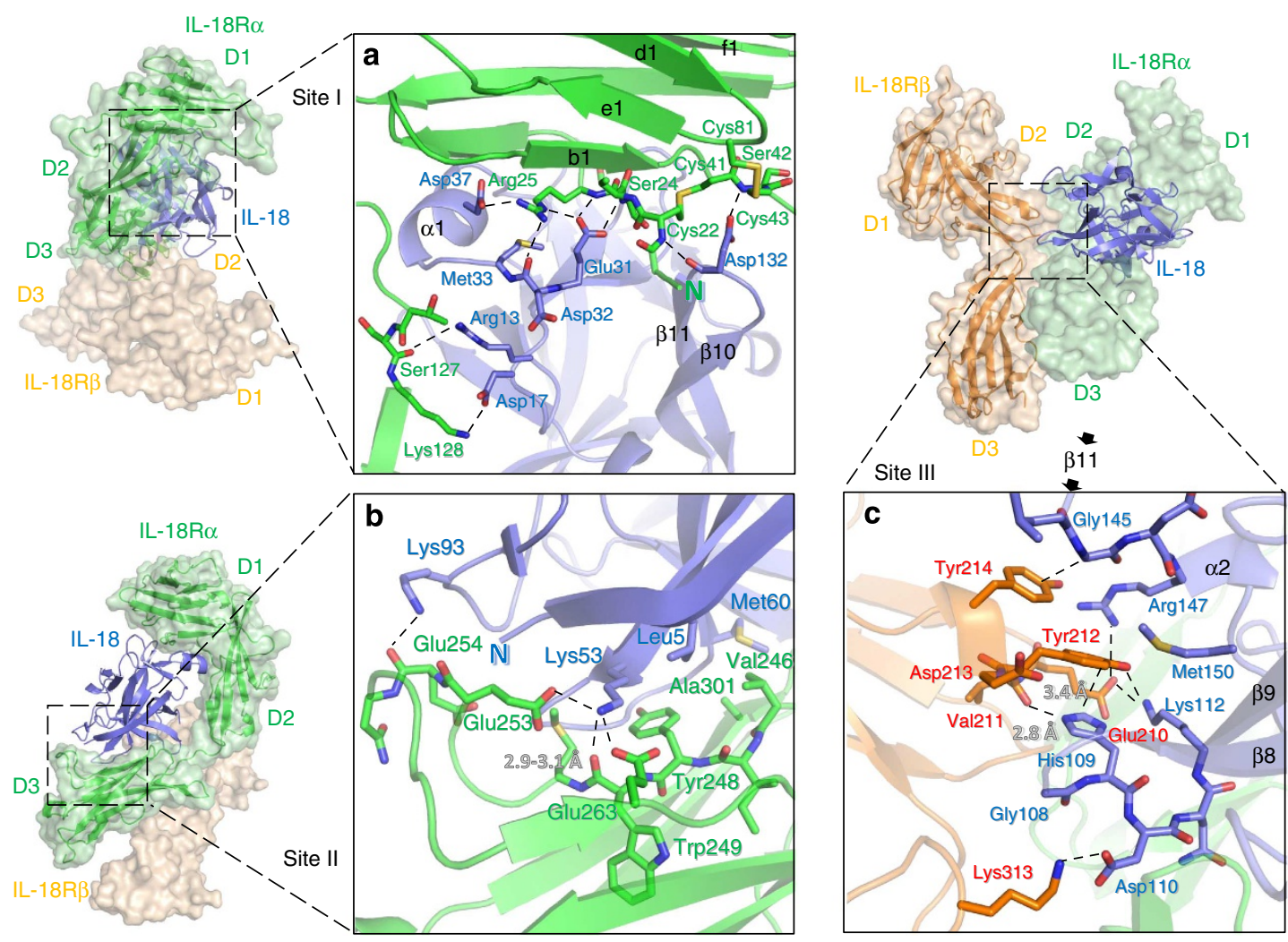

Figure 5 | The key residues involved in forming the ternary signalling complex. (a) The interactions in the IL-18 receptor binding Site I. In addition to the area surrounding the stable $\alpha$-helix I, Asp132 ${ }^{1 \mathrm{~L}-18}$ at the tip of the $\beta 10-\beta 11$ hairpin exhibits ionic interactions with the structure, which are formed by the two unique disulfide bonds in IL-18R $\alpha$. (b) Interactions surrounding the IL-18 Site II. The key residue of Lys53 $3^{\mathrm{L}-18}$ is recognized by the IL-18R $\alpha$ acidic surface through multiple hydrogen bonds. (c) The interface between Site III of IL-18 and IL-18R $\beta$. In addition to His $109^{\mathrm{IL}-18} / \mathrm{Tyr}^{\mathrm{R} 212^{\mathrm{R} \beta}}$ stacking, multiple hydrogen bonds were observed: the His109 ${ }^{\mathrm{LL}-18} \mathrm{~N} \varepsilon-\mathrm{H}$ to the $\mathrm{Val} 211^{\mathrm{R} \beta}$ backbone carbonyl oxygen as well as the Lys $112^{\mathrm{IL}-18} \mathrm{N \zeta}-\mathrm{H}$ to the $\mathrm{Glu} 210^{\mathrm{R} \beta}$ side chain

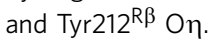

primary receptors (IL-1RI, IL-18R $\alpha$, ST2 and IL-36R $)^{29}$. Thus, certain receptors must be used by multiple ligands (Fig. 2a). In fact, IL-1RAcP is commonly involved in signals with six ligands other than IL-18, which is recognized by its specific receptors, IL- $18 \mathrm{R} \alpha$ and IL-18R $\beta$. Accordingly, the IL-18 binding mode remained unclear even after several crystal structures of the IL- $1 \beta$ and receptor complexes became available. The IL-18 complex structures determined in this work exhibited essentially the same binding mode as IL-1 $\beta^{23-25}$. This feature was confirmed under more physiological conditions by using two solution techniques, NMR and SAXS. On the basis of these results, it is highly likely that the left binding mode is the common mode in the IL-1 family; however, the IL-36/IL-36R/IL-1RAcP ternary complex structure has not been determined. Although the general binding mode was conserved, substantial differences were observed at the ligand-receptor or receptor-receptor interfaces in the IL-18 and IL-1 $\beta$ ternary complexes, which was expected based on the significant sequence deviations (Supplementary Fig. 1). The pronounced effects from such deviations include the unique compositions of secondary structure elements in IL-18R $\alpha$-D1 and IL-18Rs-D2, such as the lack of a $\beta$-strand that is typically conserved among Ig-like domains. This feature has led to the unique subdomain orientation of IL-18R $\beta$, and may partly explain why IL-1RAcP exhibits the promiscuous ligand recognition mode, although IL-18R $\beta$ does not. On the basis of the presumable existence of $\mathrm{d} 2$ in IL-36R-D2 and the IL-36 (ref. 27) structure, it is likely that the IL-36 system also adopts the left binding mode with similar orientation to the IL-1 $\beta$ system.
Furthermore, we found a potential common trait among the IL-1 family, which is that the N-linked glycans presumably bridge two receptors in the ternary complex. Intriguingly, this feature was only observed in two functional ternary complexes (IL-1 $\beta / \mathrm{IL}-1 \mathrm{RI} / \mathrm{IL}-1 \mathrm{RAcP}$ and IL-18/IL-18R $\alpha / \mathrm{IL}-18 \mathrm{R} \beta$ ) but was absent in the decoy ternary complex (IL-1 $/ /$ IL-1RII/IL-1RAcP) and may contribute the binding affinity. Nevertheless, our SPR analyses showed that the difference in IL-18R $\alpha$-binding affinity for IL-18R $\beta$ was only trivial even without glycosylation $\left(\mathrm{N} 236 \mathrm{Q}^{\mathrm{R} \alpha}\right.$ in Table 2). This discrepancy may be due to the distinct sugar modification patterns between insects and mammals. N-glycans are mostly pauci-mannose (Fig. 6b, not greater than three MAN) oligosaccharides in silkworm ${ }^{30}$, while mammals contain more varied outer sugar chains; certain chains are longer with more complicatedly mixtures (that is, MAN, NAG, galactose and sialic acid). Thus, larger interaction surfaces on $\mathrm{N} 236^{\mathrm{R} \alpha}$ sugar chains in humans are expected, which could strengthen the affinity. In contrast, one N-glycan chain likely plays a unique role in the IL-18 system, as the IL-18R $\alpha$ Asn $297^{\mathrm{R} \alpha}$ sugar chain moderately interacts with IL-18 in both the binary and ternary complexes (Fig. 6d). In fact, IL-18R $\alpha$ without the sugar chain (N297Q) exhibited a threefold lower binding affinity (Table 2). To our best knowledge, such sugar-ligand interactions have not been reported for other IL-1 family members. For the IL-1 $\beta$ complexes, any N-glycan chains on IL-1RI(RII) appear too distal to the ligand for direct contact.

IL-1 family activity in vivo are modulated by the counteractions of natural inhibitors, such as receptor antagonists (IL-1Ra, IL-36Ra and IL-38), soluble receptors (sIL-1RI, sIL-18R and 


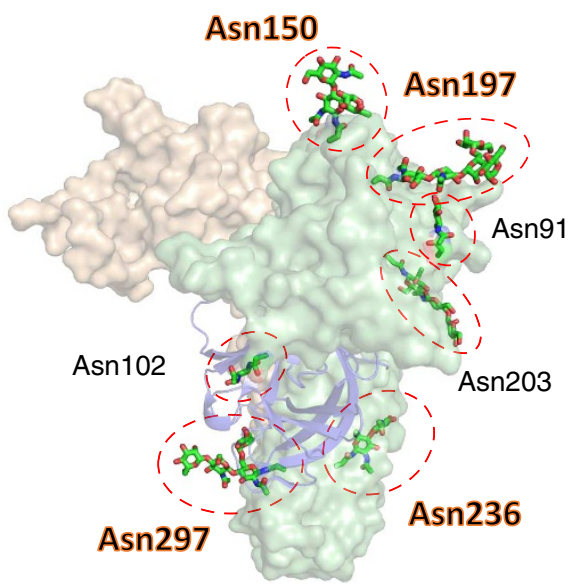

b

High-mannose (for structural analysis)

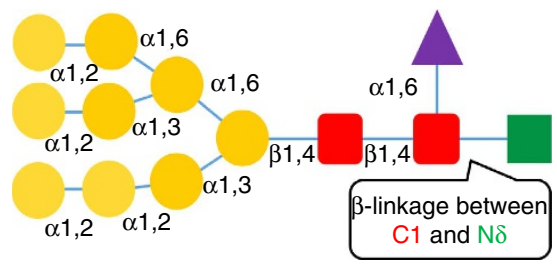

Pauci-mannose (for SPR)

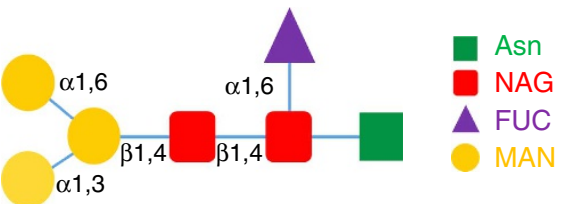

c

d

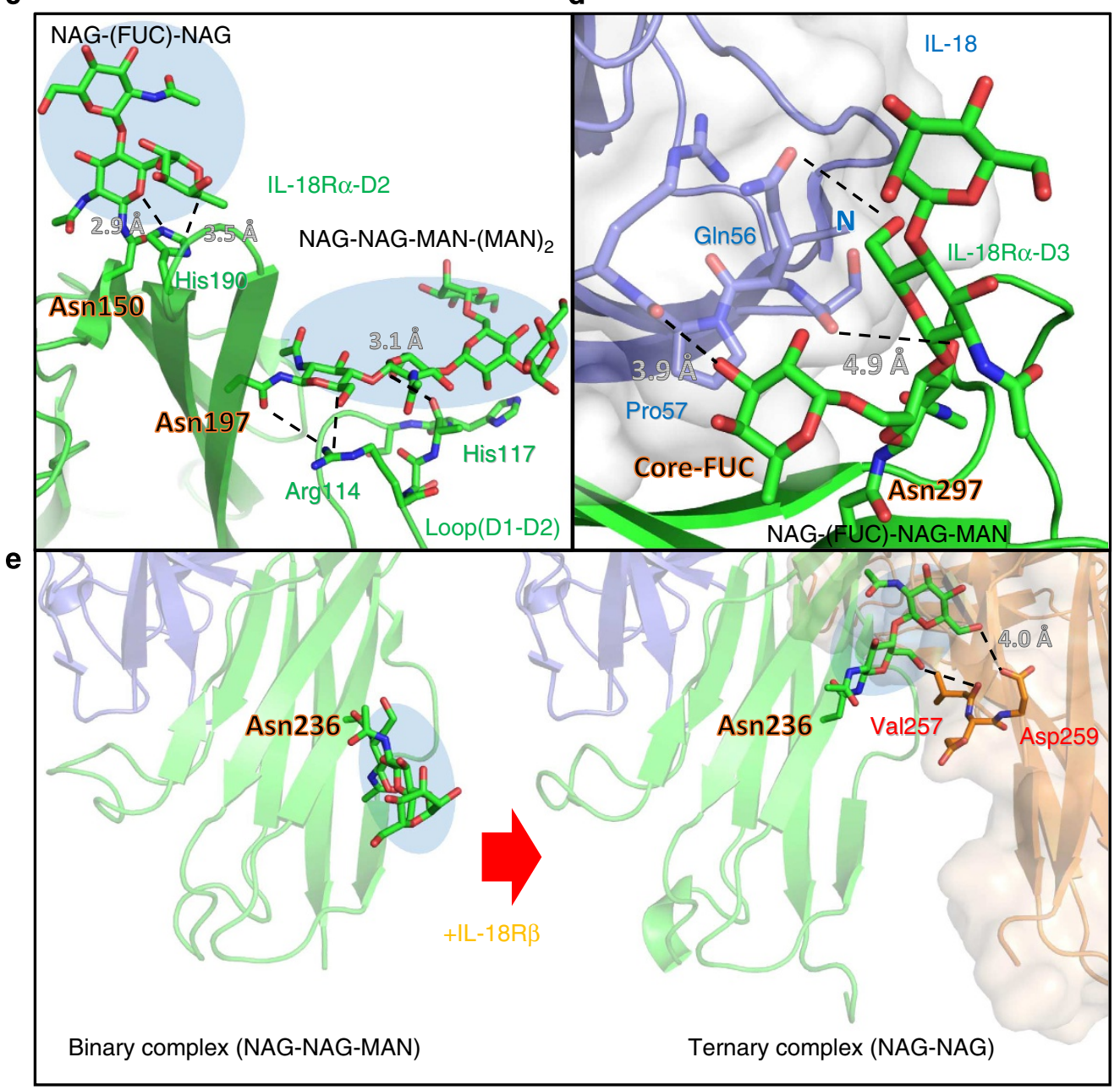

Figure 6 | The sugar contacts that maintain IL-18/IL-18R $\alpha$ /IL-18Rß. (a) The N-linked glycans identified from the structure. (b) The N-linked glycosylation in this study. (c) Intramolecular interactions between the carbohydrates on Asn150 $0^{R \alpha}$ and His190 $0^{R \alpha}$ as well as on Asn197 ${ }^{R \alpha}$ and the D1-D2 loop.

(d) Interactions between the $\mathrm{N}$-linked carbohydrates on $\mathrm{Asn} 297^{\mathrm{R} \alpha}$ and IL-18. Core-FUC moderately interacts with IL-18 at an $\sim 4 \AA$ distance.

(e) Interactions between the $\mathrm{N}$-linked carbohydrates on $A s n 236^{\mathrm{R} \alpha}$ and IL-18R $\beta$.

sST2) and IL-18BP. These proteins tightly bind their target cytokines or receptors, which impedes formation of ternary complexes that initiate intracellular signal transduction. This balancing feature facilitates secure control of inflammatory responses in vivo. Our structures not only demonstrate the receptors' molecular recognition mode for IL-18, but they also explain the IL-18 inhibitors' mechanism of action.
Superimposition of the IL-18/IL-18R $\alpha$ and IL-18/IL-18BPs complex structures ${ }^{20,22}$ shows that the IL-18BP binding site on IL-18 precisely corresponds with the IL-18R $\alpha$-D3 binding site. Thus, IL-18BP clearly inhibits IL-18R $\alpha$ binding through steric hindrance (Supplementary Fig. 8a). Recently, IL-37 (IL-1F7b) was proposed to function as an anti-inflammatory cytokine ${ }^{31}$. IL-37 weakly bound IL-18R $\alpha$ with 50 times lower affinity than IL-18 

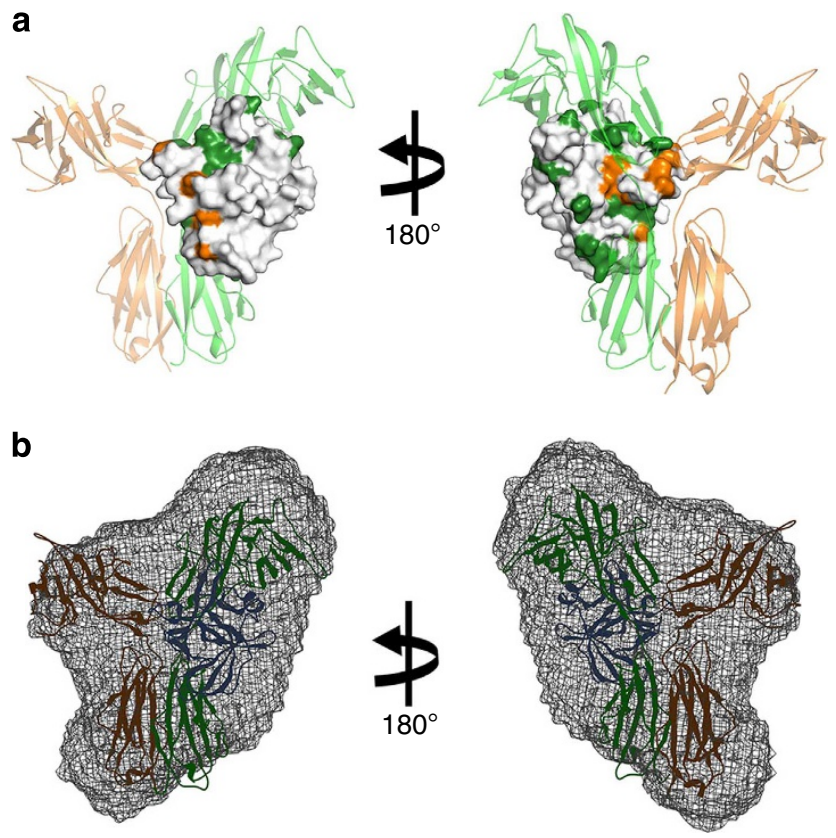

Figure 7 | The solution-state IL-18/IL-18R $\alpha /$ IL-18R $\beta$ binding mode. (a) The results of cross-saturation experiments with $\left[{ }^{2} \mathrm{H}-{ }^{15} \mathrm{~N}\right]-\mathrm{IL}-18 / \mathrm{IL}-18 \mathrm{R} \alpha$ (forest) and the chemical shift change of $\left[{ }^{2} \mathrm{H}_{-}{ }^{15} \mathrm{~N}\right]-\mathrm{IL}-18 / \mathrm{IL}-18 \mathrm{R} \alpha$ on adding IL-18R $\beta$ (orange) are coloured on the crystal structure of IL-18 in complex with IL-18R $\alpha$ and IL-18R $\beta$. (b) Superimposition of the IL-18/IL-18R $\alpha /$ IL-18R $\beta$ crystal structure and the low-resolution SAXS envelope.

a

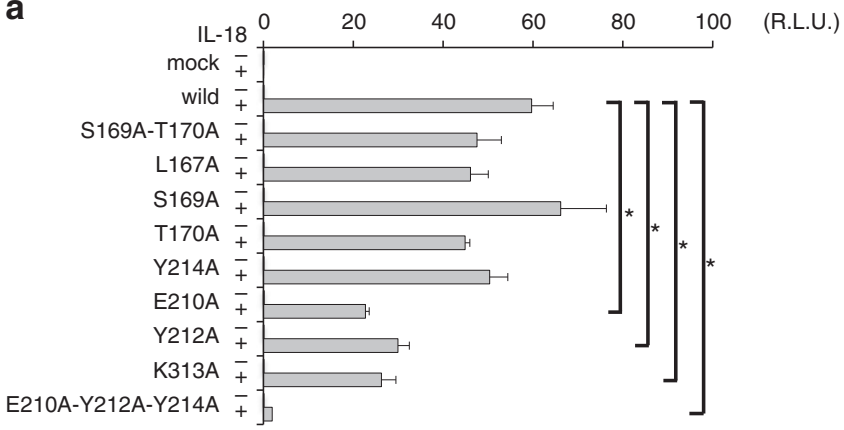

b

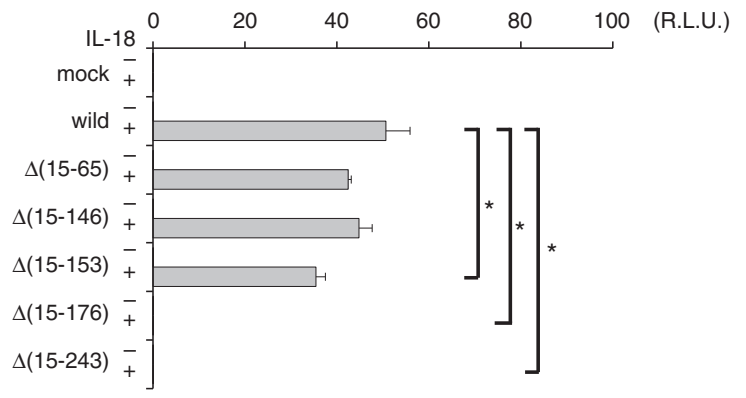

Figure 8 | The effect of mutations on protein-protein interfaces for signal transduction. Cell-based NF- $\mathrm{KB}$ activity assay for IL-18R $\beta$ with (a) an alanine substitution and (b) N-terminal deletion. Each column indicates the relative luciferase activity unit (R.L.U.), for the stimulated cells $(+)$ and the non-stimulated cells $(-)$. The data are the mean \pm s.d. for triplicate experiments. Asterisks inside the graphs indicate the significance from comparing mutant versus wild-type IL-18 R $\beta$, which was determined using a one-way ANOVA with Bonferroni's multiple comparison test; ${ }^{\star} P<0.05$. This experiment is representative of three independent experiments.
Table 2 | Functional epitopes of IL-18 and IL-18 receptors.

\begin{tabular}{lc} 
& $\boldsymbol{K}_{\mathbf{d}} \mathbf{( 1 0}^{-\mathbf{8}} \mathbf{~ M )}$ \\
\hline Ligand: IL-18R $\beta$ WT & \\
Analyte: IL-18 mutant/IL-18R $\alpha$ WT complex & \\
IL-18 WT(control) & $1.5 \pm 0.1$ \\
IL-18 G108A & No binding \\
IL-18 H109A & No binding \\
IL-18 D110A & $5.6 \pm 0.8$ \\
IL-18 K112A & No binding \\
IL-18 G145A & $2.8 \pm 0.1$ \\
IL-18 R147A & $5.7 \pm 0.3$ \\
IL-18 M150A & $6.0 \pm 0.5$
\end{tabular}

Ligand: IL-18R $\beta$ mutant

Analyte: IL-18 WT/IL-18R $\alpha$ WT complex

$\begin{array}{ll}\text { IL-18R } \beta \text { WT (control) } & 1.5 \pm 0.1\end{array}$

IL-18R $\beta$ L167A $\quad 3.3 \pm 0.4$

$\begin{array}{ll}\text { IL-18R } \beta \text { E210A } & 32.7 \pm 0.9\end{array}$

IL-18R $\beta$ Y212A No binding

IL-18R $\beta$ Y 214A $\quad 5.0 \pm 0.5$

$\begin{array}{ll}\text { IL-18R } \beta \text { K313A } & 10.9 \pm 0.9\end{array}$

Ligand: IL-18R $\beta$ WT

Analyte: IL-18WT/IL-18R $\alpha$ mutant complex

IL-18R $\alpha$ WT (control) $\quad 1.5 \pm 0.1$

$\begin{array}{ll}\text { IL-18R } \alpha \text { N236Q } & 1.7 \pm 0.3\end{array}$

Ligand: IL-18R $\alpha$ mutant

Analyte: IL-18 WT

$\begin{array}{lr}\mathrm{IL}-18 \mathrm{R} \alpha \mathrm{WT} \text { (control) } & 6.9 \pm 0.2\end{array}$

IL-18R $\alpha$ N297Q $25.8 \pm 2.6$

Ligand: the interactant captured on the sensor surface. Analyte: the interactant in free solution. WT: wild type. Values are the means \pm s.d. of the results derived from three independent experiments.

(Fig. 2a), and did not activate signal transduction ${ }^{32}$. Consistent with this notion, the essential IL-18 amino acids for the IL-18R $\beta$ interactions, as well as for IL-18R $\alpha$, determined in this study are not conserved in IL-37 (Supplementary Fig. 1a), which suggests that IL-37 is incapable of forming the ternary complex that enables signal transduction. In addition to the natural inhibitors, several anti-IL-18 antibodies have been developed for therapeutic purposes $^{21,33}$. The structures herein clearly explain how these antibodies impede binding between the ligand and receptors (Supplementary Fig. 8b).

The molecular interface differences herein are important because they may provide numerous opportunities for designing molecules that specifically stabilize or interrupt IL-18 ternary complex formation without affecting other IL-1 family members. Unlike molecules that target more downstream signalling pathways, these molecules can be used to treat ligand-specific diseases and avoid side effects due to interference with common intracellular signalling pathways. The structural information collected in this work will facilitate development of an IL-18 modulator in multiple ways. For example, recombinant derivatives of IL-18, which bind to IL-18R $\alpha$ more strongly relative to wild type of IL-18, can be logically designed based on the structures ${ }^{34}$. The structures will especially benefit small molecule design; small molecules are generally more cost effective once developed, and thus preferable to proteinous compounds. The data obtained in this study provide an atomic framework for molecular interfaces between IL-18 and receptors as well as between the two receptors, which serve as promising drug target sites, and hence will aid in development of effective IL-18 inhibitors. 
In summary, the structures of IL-18 and its receptor have advanced our precise understanding of molecular recognition and suggest a single architectural paradigm for signalling complexes in the IL-1 family cytokines. Furthermore, with biochemical and cellular data, the structures reveal detailed interaction properties at the molecular interfaces, presenting an atomic framework that will aid in rational drug development for IL-18-related diseases.

\section{Methods \\ Construction of expression vectors. The coding region of the extracellular} domains of human IL-18R $\alpha$ (NM_003855, residues 20-329) and IL-18R $\beta$ (NM_003853, residues 15-356) were cloned into the pFastBac1 vector (Invitrogen, Carlsbad, CA, USA). Full-length IL-18R $\beta$ was also cloned into the pcDNA3.1+ vector (Invitrogen). The pGL4.32[luc2P/NF- $\kappa \mathrm{B}-\mathrm{RE} /$ Hygro] vector was used as an $\mathrm{NF}-\kappa \mathrm{B}$ luciferase reporter, and the pGL4.70[hRluc] vector was used as an internal control Renilla luciferase reporter; both were purchased from Promega (Fitchburg, WI, USA). For the crystallographic studies, the signal-peptide sequence for Sf9 insect cells, an $8 \times$ His tag and an HRV 3C protease cleavage site were placed immediately upstream of the mature sequence ${ }^{35}$. The same constructs with a C-terminal $6 \times$ His tag and without the HRV 3C site were also prepared for solution structure analysis and SPR experiments. Mutations were introduced into the pGEX4T-1 [IL-18 $]^{19}$, pFastBac1[IL-18Rs] and pcDNA3.1 + [IL-18R $\left.\beta\right]$ vectors using an inverse PCR-based site-directed mutagenesis method.

Protein expression and purification. Mature IL-18 (residues 1-157) and its single amino-acid mutants were prepared as previously reported ${ }^{19}$. In brief, human IL-18 was expressed as a glutathione S-transferase (GST) fusion protein in the Escherichia coli strain BL21(DE3) (Novagen, Madison, WI, USA). GST-tagged IL-18 was affinity purified followed by GST digestion with Factor Xa and further purified using gel filtration column chromatography. Expression of IL-18Rs using Sf9 insect cell system and their detailed purification procedures were also described ${ }^{35}$. The extracellular human IL-18R $\alpha$ or IL-18R $\beta$ domains were each separately secreted from Sf9 insect cells (Invitrogen) for structural analyses. The supernatant was purified through three chromatography steps, including ion exchange chromatography, Ni-NTA affinity chromatography and gel filtration chromatography with or without an HRV 3C treatment. To obtain the IL-18/IL$18 \mathrm{R} \alpha$ binary and IL-18/IL-18R $\alpha / \mathrm{IL}-18 \mathrm{R} \beta$ ternary complexes, IL-18, IL-18R $\alpha$ and IL-18R $\beta$ were mixed at equimolar ratios and purified through gel filtration chromatography. Both the wild type and the mutants of the IL-18Rs for SPR analysis were expressed using a silkworm system ${ }^{36,37}$. The donor plasmids of the pFastBacl vectors containing the IL-18 receptor gene were transformed into Escherichia coli BmDH10Bac. Then, $1 \mu \mathrm{g}$ of BmNPV bacmid DNA and $1 \mu \mathrm{l}$ of Cellfectin reagent (Invitrogen) suspended in Grace insect cell medium were injected into the ventral side of $B$. mori silkworm larvae. After 6 days, haemolymph was recovered from the larvae, and sodium thiosulfate (final $0.5 \%$ ) and EDTA were immediately added. The IL-18 receptor proteins from the silkworm were purified using the same protocols as the purification from the Sf9 insect cell system.

Cell culture. HEK293 cells (Japanese Collection of Research Bioresources, Osaka, Japan) were cultured in Dulbecco's modified Eagle's medium (high glucosecontaining D-MEM, Invitrogen) supplemented with $10 \%$ heat-inactivated fetal bovine serum (Sigma-Aldrich, Missouri, USA), penicillin (100 unit $\mathrm{ml}^{-1}$ ) and streptomycin $\left(100 \mu \mathrm{g} \mathrm{ml}^{-1}\right)$. All cells were incubated at $37^{\circ} \mathrm{C}$ in a humidified atmosphere of $5 \% \mathrm{CO}_{2}$

Luciferase reporter gene assay. HEK293 cells were transfected with an empty pcDNA3.1 + vector or pcDNA3.1 + [IL-18R $\beta]$ (wild-type or mutants), pGL4.32[luc2P/NF- $\mathrm{BB}-\mathrm{RE} /$ Hygro] and pGL4.70[hRluc] vectors using Lipofectamine 2000 reagent according to the manufacturer's instructions. These transfectants were stimulated with recombinant human IL-18 $\left(10 \mathrm{ng} \mathrm{ml}^{-1}\right)$ for $6 \mathrm{~h}$. The luciferase reporter gene activities were analysed using a Dual-Luciferase Reporter Assay System (Promega). The statistical significance of the differences was determined using one-way ANOVA with Bonferroni's multiple comparison test. The statistical significance was assigned to be $P<0.05$.

Surface plasmon resonance analysis. The real-time binding affinities between IL-18 and IL-18R $\alpha$ and between IL-18R $\beta$ and IL-18/IL-18R $\alpha$ were analysed using a BIAcore 3000 surface plasmon resonance spectrometer (GE Healthcare, Little Chalfont, UK) at $25^{\circ} \mathrm{C}$ with a Ni-NTA sensor chip. The $K_{\mathrm{d}}$ (dissociation constant) estimated using the Ni-NTA sensor chip was an average of one order of magnitude lower than estimates obtained using an Anti-His-tag Ab covalently linked to a CM5 sensor chip. However, we used the Ni-NTA sensor chip because it did not decrease the binding capacity after repeated measurement cycles, which is desirable when comparing the $K_{\mathrm{d}}$ of many mutants.
C-terminal $6 \times$ His tagged IL-18R $\alpha$ was immobilized approximately 200 -resonance units (RU) on an NTA sensor chip. Then, various concentrations of IL-18 in HBS-P (10 mM HEPES-Na, pH7.4, $150 \mathrm{mM} \mathrm{NaCl}, 0.01 \%$ (v/v) surfactant $\mathrm{P}-20)$ buffer were injected over the sensor surface as an analyte at a flow rate of $30 \mu \mathrm{l} \mathrm{min}{ }^{-1}$ for $180 \mathrm{~s}$. After association, it was allowed to run for another $360 \mathrm{~s}$ for dissociation. In the same way, C-terminal $6 \times$ His tagged IL-18R $\beta$ was immobilized approximately $100 \mathrm{RU}$ on the sensor chip, and un-tagged IL-18R $\alpha$ that was saturated with $500 \mathrm{nM}$ IL-18 in HBS-P buffer was injected. The sensor surface was regenerated with $350 \mathrm{mM}$ EDTA. For the mutational analysis, mutants of IL-18, IL-18R $\alpha$ and IL-18R $\beta$ were used instead of wild type, as shown in Supplementary Table 1 . The sensor chip was analysed using BIAevaluation software (GE Healthcare). Analyses with the same concentration series were performed in triplicate.

Crystal structure determination. Step by step crystallization method and preliminary crystallographic analysis were done as described ${ }^{35}$. X-ray diffraction data were collected at $100 \mathrm{~K}$ on the BL38 (IL-18) or BL44XU (IL-18/IL-18R $\alpha$ ) beamlines at SPring- 8 (Harima, Japan) and on the BL17A beamline (IL-18/IL-18R $\alpha /$ IL-18R $\beta$ ) at Photon Factory (Tsukuba, Japan). For IL-18 and IL-18/IL-18R $\alpha$, the diffraction data were processed using the $\mathrm{XDS}^{38}$ and SCALA ${ }^{39,40}$ software. The initial phases were determined by molecular replacement using Phaser ${ }^{41}$ with the crystal structure of IL-18 (ref. 20) (PDB code: 3F62) as the search model. The initial phases of the binary complex were improved by NCS averaging using RESOLVE ${ }^{42}$. The model was further manually built using COOT $^{43}$ and refined using BUSTER ${ }^{44}$ with autoNCS ${ }^{45}$. In the IL-18 and IL-18/IL-18R $\alpha$ crystals, four and six copies of IL-18 and the binary complexes were observed in each ASU, respectively. The structures of these copies in the ASUs are essentially the same, so we referred to chain A for IL-18 and chain A/B for IL-18/IL-18R $\alpha$, if not otherwise indicated. The structure of IL-18 included 13 molecules of CHAPS. The diffraction data of IL-18/ IL-18R $\alpha /$ IL-18R $\beta$ were processed using HKL2000 software ${ }^{46}$. To determine the initial phase for IL-18/IL-18R $\alpha / \mathrm{IL}-18 \mathrm{R} \beta$, a refined structure of the binary complex was used as the search model for molecular replacement. The model was further manually built using COOT and refined using BUSTER. Only one copy of the ternary complex was in the IL-18/IL-18R $\alpha /$ IL-18R $\beta$ crystal ASU. Ramachandran diagrams were examined using RAMPAGE ${ }^{47}$. Structural figures were prepared using PyMol (Schrödinger, LLC). The secondary structures were assigned using the DSSP software ${ }^{48}$

NMR spectroscopy. All NMR spectra were measured at $308 \mathrm{~K}$ on a Bruker Avance II $700 \mathrm{MHz}$ spectrometer equipped with cryogenic probes using TROSYtype pulse sequences. The samples for NMR measurements were in $20 \mathrm{mM}$ potassium phosphate ( $\mathrm{pH} 6.0), 50 \mathrm{mM} \mathrm{KCl}$ in $\mathrm{H}_{2} \mathrm{O} / \mathrm{D}_{2} \mathrm{O}(90 \% / 10 \%)$. Spectra were processed using NMRPipe ${ }^{49}$ and analysed using Sparky analysis software ${ }^{50}$

Chemical shift assignments for IL-18 bound to IL-18R $\alpha$ are based on a $\mathrm{HN}(\mathrm{CO}) \mathrm{CA} / \mathrm{HNCA}$ data set and confirmed by HNCACB and NOESY spectra with a mixing time of $200 \mathrm{~ms}$. The IL- $18 \mathrm{R} \alpha$ binding surface of IL-18 in solution is defined by the cross-saturation ${ }^{28}$ intensity ratio of $\mathrm{I}_{2000 \mathrm{~ms}} / \mathrm{I}_{0 \mathrm{~ms}}$. The IL-18R $\beta$ binding site of IL-18 is inferred from the titration experiment, by shifted or eliminated peaks, which can be assigned for all but the IL-18R $\alpha$ binding surface. Structural figures were prepared using PyMol (Schrödinger, LLC).

Small-angle X-ray scattering. SAXS data of the IL-18/IL-18R $\alpha /$ IL-18R $\beta$ ternary complex were collected at the beamline 12ID-B of the Advanced Photon Source at Argonne National Laboratory (Argonne, IL, USA). The sample concentrations were 1,3 and $5 \mathrm{mg}^{-1} \mathrm{ml}^{-1}$. The samples were run at $12 \mathrm{keV}$ radiation energy, with a sample-to-detector distance of $2 \mathrm{~m}$. The scattered X-rays were measured using a Pilatus $2 \mathrm{M}$ detector. A flow cell was used to reduce radiation damage. Thirty images were taken for each blank and each sample.

After background subtraction, the data were superimposed using Primus ${ }^{5}$ (Supplementary Fig. 4f). $S$ is the momentum transfer equal to $4 \pi \sin (\theta / 2) / \lambda$, where $\theta$ and $\lambda$ are the scattering angle and $\mathrm{X}$-ray wavelength, respectively. $R_{\mathrm{g}}$ is the radius of gyration, which was determined using the Guinier approximation of the data in the low $s$ region $\left(s R_{\mathrm{g}}<1.3\right)$, the linearity of which also served as an initial assessment of data quality (Supplementary Fig. $4 \mathrm{~g}$ ). The maximum particle dimension, $D_{\max }$, and the distance distribution function, $P(r)$, were calculated using auto GNOM ${ }^{52}$ (Supplementary Fig. $4 \mathrm{~h}$ ). The low-resolution envelopes of the ternary complex were produced using DAMMIN ${ }^{53}$ by directly fitting the reciprocal space scattering profile. Fifteen DAMMIN models were generated and then aligned and averaged using DAMAVER and DAMFILT ${ }^{54}$. Structural figures were prepared using Chimera 55 .

\section{References}

1. Okamura, H. et al. Cloning of a new cytokine that induces IFN-gamma production by T cells. Nature 378, 88-91 (1995).

2. Kuida, K. et al. Altered cytokine export and apoptosis in mice deficient in interleukin-1 beta converting enzyme. Science 267, 2000-2003 (1995).

3. Li, P. et al. Mice deficient in IL-1 beta-converting enzyme are defective in production of mature IL-1 beta and resistant to endotoxic shock. Cell $\mathbf{8 0}$, 401-411 (1995). 
4. Ghayur, T. et al. Caspase-1 processes IFN-gamma-inducing factor and regulates LPS-induced IFN-gamma production. Nature 386, 619-623 (1997).

5. Rathinam, V. a. K., Vanaja, S. K. \& Fitzgerald, K. a. Regulation of inflammasome signaling. Nat. Immunol. 13, 333-2 (2012).

6. Ohnishi, H. et al. TRAM is involved in IL-18 signaling and functions as a sorting adaptor for MyD88. PLoS ONE 7, e38423 (2012).

7. Adachi, O. et al. Targeted disruption of the MyD88 gene results in loss of IL-1and IL-18-mediated function. Immunity 9, 143-150 (1998).

8. Hoffman, H. M., Mueller, J. L., Broide, D. H., Wanderer, A. A. \& Kolodner, R. D. Mutation of a new gene encoding a putative pyrin-like protein causes familial cold autoinflammatory syndrome and Muckle-Wells syndrome. Nat. Genet. 29, 301-305 (2001).

9. Park, H., Bourla, A. B., Kastner, D. L., Colbert, R. a. \& Siegel, R. M. Lighting the fires within: the cell biology of autoinflammatory diseases. Nat. Rev. Immunol. 12, 570-580 (2012)

10. Dinarello, C. a., Simon, A. \& van der Meer, J. W. M. Treating inflammation by blocking interleukin-1 in a broad spectrum of diseases. Nat. Rev. Drug Discov. 11, 633-652 (2012)

11. Alboni, S., Cervia, D., Sugama, S. \& Conti, B. Interleukin 18 in the CNS J. Neuroinflamm. 7, 9 (2010).

12. Mellins, E. D., Macaubas, C. \& Grom, A. A. Pathogenesis of systemic juvenile idiopathic arthritis: some answers, more questions. Nat. Rev. Rheumatol. 7, 416-426 (2011).

13. Hirota, T. et al. Genome-wide association study identifies eight new susceptibility loci for atopic dermatitis in the Japanese population. Nat. Genet. 44, 1222-1226 (2012).

14. Dinarello, C. A., Novick, D., Kim, S. \& Kaplanski, G. Interleukin-18 and IL-18 binding protein. Front. Immunol. 4, 289 (2013).

15. Romberg, N. et al. Mutation of NLRC4 causes a syndrome of enterocolitis and autoinflammation. Nat. Genet. 46, 1135-1139 (2014).

16. Canna, S. W. et al. An activating NLRC4 inflammasome mutation causes autoinflammation with recurrent macrophage activation syndrome. Nat. Genet. 46, 1140-1146 (2014).

17. Terada, M. et al. Contribution of IL-18 to atopic-dermatitis-like skin inflammation induced by Staphylococcus aureus product in mice. Proc. Natl Acad. Sci. USA 103, 8816-8821 (2006)

18. Brydges, S. D. et al. Divergence of IL-1, IL-18, and cell death in NLRP3 inflammasomopathies. J. Clin. Invest. 123, 4695-4705 (2013).

19. Kato, Z. et al. The structure and binding mode of interleukin-18. Nat. Struct. Biol. 10, 966-971 (2003).

20. Krumm, B., Meng, X., Li, Y., Xiang, Y. \& Deng, J. Structural basis for antagonism of human interleukin 18 by poxvirus interleukin 18-binding protein. Proc. Natl Acad. Sci. USA 105, 20711-20715 (2008).

21. Argiriadi, M. A., Xiang, T., Wu, C., Ghayur, T. \& Borhani, D. W. Unusual water-mediated antigenic recognition of the proinflammatory cytokine interleukin-18. J. Biol. Chem. 284, 24478-24489 (2009).

22. Krumm, B., Meng, X., Wang, Z., Xiang, Y. \& Deng, J. A unique bivalent binding and inhibition mechanism by the yatapoxvirus interleukin 18 binding protein. PLoS Pathog. 8, e1002876 (2012).

23. Wang, D. et al. Structural insights into the assembly and activation of IL-1 $\beta$ with its receptors. Nat. Immunol. 11, 905-911 (2010).

24. Thomas, C., Bazan, J. F. \& Garcia, K. C. Structure of the activating IL-1 receptor signaling complex. Nat. Struct. Mol. Biol. 19, 455-457 (2012).

25. Liu, X. et al. Structural insights into the interaction of IL-33 with its receptors. Proc. Natl. Acad. Sci. USA 110, 14918-14923 (2013).

26. Vigers, G. P., Anderson, L. J., Caffes, P. \& Brandhuber, B. J. Crystal structure of the type-I interleukin-1 receptor complexed with interleukin-1beta. Nature 386, 190-194 (1997).

27. Günther, S. \& Sundberg, E. J. Molecular determinants of agonist and antagonist signaling through the IL-36 receptor. J. Immunol. 193, 921-930 (2014).

28. Takahashi, H., Nakanishi, T., Kami, K., Arata, Y. \& Shimada, I. A novel NMR method for determining the interfaces of large protein-protein complexes. Nat. Struct. Biol. 7, 220-223 (2000).

29. Garlanda, C., Dinarello, C. a. \& Mantovani, A. The interleukin-1 family: back to the future. Immunity 39, 1003-1018 (2013).

30. Park, E. Y. et al. Human IgG1 expression in silkworm larval hemolymph using BmNPV bacmids and its N-linked glycan structure. J. Biotechnol. 139, 108-114 (2009).

31. Nold, M. F. et al. IL-37 is a fundamental inhibitor of innate immunity. Nat. Immunol. 11, 1014-1022 (2010).

32. Kumar, S. et al. Interleukin-1F7B (IL-1H4/IL-1F7) is processed by caspase-1 and mature IL-1F7B binds to the IL-18 receptor but does not induce IFN-gamma production. Cytokine 18, 61-71 (2002).

33. Hamasaki, T. et al. Human anti-human IL-18 antibody recognizing the IL-18-binding site 3 with IL-18 signaling blocking activity. J. Biochem. 138, 433-442 (2005)
34. Kim, S. H. et al. Site-specific mutations in the mature form of human IL-18 with enhanced biological activity and decreased neutralization by IL-18 binding protein. Proc. Natl Acad. Sci. USA 98, 3304-3309 (2001).

35. Kimura, T. et al. Purification, crystallization and preliminary X-ray crystallographic analysis of human IL-18 and its extracellular complexes. Acta Crystallogr. Sect. F, Struct. Biol. Commun. 70, 1351-1356 (2014).

36. Motohashi, T., Shimojima, T., Fukagawa, T., Maenaka, K. \& Park, E. Y. Efficient large-scale protein production of larvae and pupae of silkworm by Bombyx mori nuclear polyhedrosis virus bacmid system. Biochem. Biophys. Res. Commun. 326, 564-569 (2005).

37. Kajikawa, M. et al. Silkworm Baculovirus Expression System for Molecular Medicine. J. Biotechnol. Biomater. S9, 1-5 (2012).

38. Kabsch, W. Xds.. Acta Crystallogr. D. Biol. Crystallogr. 66, 125-132 (2010).

39. Evans, P. Scaling and assessment of data quality. Acta Crystallogr. D. Biol. Crystallogr. 62, 72-82 (2006).

40. Evans, P. R. An introduction to data reduction: space-group determination, scaling and intensity statistics. Acta Crystallogr. D. Biol. Crystallogr. 67, 282-292 (2011)

41. McCoy, A. J. et al. Phaser crystallographic software. J. Appl. Crystallogr. 40, 658-674 (2007).

42. Terwilliger, T. C. Statistical density modification with non-crystallographic symmetry. Acta Crystallogr. D. Biol. Crystallogr. 58, 2082-2086 (2002).

43. Emsley, P. \& Cowtan, K. Coot: model-building tools for molecular graphics. Acta Crystallogr. D. Biol. Crystallogr. 60, 2126-2132 (2004).

44. Bricogne, G. et al. BUSTER. 2.10.0 Ed., Global Phasing Ltd, UK (2011).

45. Smart, O. S. et al. Exploiting structure similarity in refinement: automated NCS and target-structure restraints in BUSTER. Acta Crystallogr. D. Biol. Crystallogr. 68, 368-380 (2012)

46. Otwinowski, Z. \& Minor, W. Processing of X-ray diffraction data collected in oscillation mode. Methods Enzymol. 276, 307-326 (1997).

47. Lovell, S. C. et al. Structure validation by Calpha geometry: phi,psi and Cbeta deviation. Proteins 50, 437-450 (2003).

48. Joosten, R. P. et al. A series of PDB related databases for everyday needs. Nucleic Acids Res. 39, D411-D419 (2011).

49. Delaglio, F. et al. NMRPipe: a multidimensional spectral processing system based on UNIX pipes. J. Biomol. NMR 6, 277-293 (1995).

50. Lee, W., Westler, W. M., Bahrami, A., Eghbalnia, H. R. \& Markley, J. L. PINE-SPARKY: graphical interface for evaluating automated probabilistic peak assignments in protein NMR spectroscopy. Bioinformatics 25, 2085-2087 (2009).

51. Konarev, P. V., Volkov, V. V., Sokolova, A. V., Koch, M. H. J. \& Svergun, D. I. PRIMUS: a Windows PC-based system for small-angle scattering data analysis. J. Appl. Crystallogr. 36, 1277-1282 (2003).

52. Svergun, D. I. Determination of the regularization parameter in indirecttransform methods using perceptual criteria. J. Appl. Crystallogr. 25, 495-503 (1992).

53. Svergun, D. I. Restoring low resolution structure of biological macromolecules from solution scattering using simulated annealing. Biophys. J. 76, 2879-2886 (1999).

54. Volkov, V. V. \& Svergun, D. I. Uniqueness of ab initio shape determination in small-angle scattering. J. Appl. Crystallogr. 36, 860-864 (2003).

55. Pettersen, E. F. et al. UCSF Chimera-a visualization system for exploratory research and analysis. J. Comput. Chem. 25, 1605-1612 (2004).

\section{Acknowledgements}

X-ray data collection was supported by SPring-8 (Harima, Japan), Photon Factory (Tsukuba, Japan), Argonne National Laboratory (Illinois, USA, supported by DE-AC0206CH11357) and Platform for Drug Discovery, Informatics, and Structural Life Science (Japan). We thank T. Tsunaka (Kyoto University) for the use of his beam time of BL44XU at SPring-8. We also thank T. Fukao, N. Kawamoto, K. Tsuji, M. Yamamoto, S. Ninomiya, T. Yano and K. Kasahara (Gifu University) for their scientific advice or technical help. Affymetrix, Inc. provided discontinued detergents to us. SAXS graphics were prepared using the UCSF Chimera package, which developed by the group at the University of California. (San Francisco, USA, supported by NIGMS P41-GM103311). This work was supported by JSPS KAKENHI Grant Number 22370038 to H.T., Grantin-Aid for JSPS Fellows to N.T., Health and Labour Science Research Grants for Research on Intractable Diseases from the Ministry of Health, Labour and Welfare to H.O., Health and Labour Science Research Grants for Research from the Ministry of Health, Labour and Welfare to Z.K., Science Research Grant from Eishukai to Z.K, and MEXT KAKENHI Grant Number 21790979 to T.K.

\section{Author contributions}

H.T. and Z.K. designed the work; M.S and N.K. supervised the study; N.T. carried out the experimental design, experiments and structural analyses, supported by T.K., K.A., M.A and H.T.; T.K. prepared the samples for the study, supported by H.O., N.T., K.M. and E.Y.P.; T.K. performed and analysed the SPR experiments; T.Y. performed the cell assays, 
supported by H.O. and T.K.; X.Z. performed the SAXS measurements; and N.T., T.K., K.A., H.O., Z.K. and H.T. contributed to writing the manuscripts and preparing the figures.

\section{Additional information}

Accession codes: The atomic coordinates and structure factors for IL-18, IL-18/IL-18R $\alpha$ and IL-18/IL-18R $\alpha / \mathrm{IL}-18 \mathrm{R} \beta$ have been deposited in the RCSB Protein Data Bank under accession codes $3 \mathrm{WO} 2,3 \mathrm{WO} 3$ and $3 \mathrm{WO} 4$, respectively.

Supplementary Information accompanies this paper at http://www.nature.com/ naturecommunications

Competing financial interests: The authors declare no competing financial interests.
Reprints and permission information is available online at http://npg.nature.com/ reprintsandpermissions/

How to cite this article: Tsutsumi, N. et al. The structural basis for receptor recognition of human interleukin-18. Nat. Commun. 5:5340 doi: 10.1038/ncomms6340 (2014).

\section{(c) (i)}

This work is licensed under a Creative Commons Attribution 4.0 International License. The images or other third party material in this article are included in the article's Creative Commons license, unless indicated otherwise in the credit line; if the material is not included under the Creative Commons license, users will need to obtain permission from the license holder to reproduce the material. To view a copy of this license, visit http://creativecommons.org/licenses/by/4.0/ 